\title{
Beiträge zur pathologischen Anatomie des Auges nach Versuchen an Thieren
}

von

\author{
Dr. C. Ritter.
}

Die pathologisch-anatomische Richtung, von welcher die Medicin ihre Fortbildung jetzt hauptsächlich erwartet, hat sich sehr bald auch in der Ophthalmologie geltend gemacht. Allein hier gingen anfangs besonders die Fortschritte so ausserordentlich langsam und so wenig dem übrigen Standpunkte dieses Zweiges entsprechend, dass Donders zu dem Hülfsmittel griff, die Augen jeder I.eiche auf anatomische Veränderungen zu untersuchen. Allein die Augen der Leichen sind nur selten in einem \%ustande zu bekommen, dass sie über die bestandenen Veränderungen sichere Auskunft geben; ausserdem sind frisch entstandenc Augenkrankheiten nur ausnahmsweise bei ihnen zu finden. Weit entschiedener sind die Fortschritte gewesen, seit man in der Kxstirpation eines verlorenen Auges einen Schutz für das erkrankende andere kennen gelernt hat. Es sind dadurch die Beobachtungen viel häufiger geworden und häufen sich immer mehr; aber einerseits betrifft die weitaus grössere Mehrzahl nur abgelaufene Prozesse, deren Natur und Anfang nur sehr hypothetisch oder selbst gar nicht aus dem Befunde $z u$ bestimmen ist; andererseits sind es nur einzelne Beobachtungen, welche allein doch noch keine Regel aufzuArchiv für Ophthalmologie. VIII. 1. 
stellen erlauben. Diesem Mangel lässt sich durch Experimente an Thieren abhelfen und sind die Resultate, welche auf diese Weise gewonnen werden, durchaus der Art, dass sie mit sehr geringen Modificationen auf den Menschen übertragen werden können, da der Bau des Auges beim Menschen und bei den höheren Säugethieren nur in Nebensachen verschieden ist. -

Versuche in dieser Richtung sind schon früher von Dieterich*), Beger**) und Werneck***) gemacht; so verdienstlich diese Arbeiten sind, so gingen sie doch häufig von ganz falschen Ansichten über den anatomischen Bau des Auges aus und unterlagen daher einer unrichtigen Fragestellung; dann aber fehlte der damaligen Zeit noch der richtige Gebrauch des Mikroskopes und damit die richtige Anschauung über den feineren Bau der Gewebe. Es wird daher eine'Wiederholung jener Versuche vielleicht nicht ganz unnütz sein, wenn auch die aus ihnen gezogenen Resultate zuweilen ganz das Richtige treffen.

Einen anderen Versuch hat dann $\mathrm{His}$ †) gemacht; wie glänzend derselbe ausgefallen ist, lehrt schon jetzt die Geschichte der pathologischen Anatomie; doch betraf er nur ein Aussenwerk des Auges und ging von ganz anderen Gesichtspunkten, als denen der Ophthalmologie aus. In einer ähnlichen Richtung hat C. O. Weber ††)

*) Dieterich, über dic Verwundungen des Linsensystems. Tïbingen 1824 .

**) Beger, über die Verwundbarkeit des Auges und seiner Häute, Zeitschrift für die Ophthalmologie von Dr, von Ammon Band III Heft 11833.

***) Werneck, einige Resultate meiner Experimente über die traumatische Reaction bei Verwundungen der Capsel und der Iinse. Zeitschrift für die Ophthalmologie von Dr. von Ammon, Band IV Heft 1. 1834.

†) His, Beiträge zur normalen und pathologischen Histologie der Hornhaut. 1856.

††) I. O. Weber, über den Bau des Glaskörpers ets. Virchnw's Archiv XIX 3 und 4. 
gearbeitet, doch kam mir scine Arbeit erst nach Vollenlung dieses Aufsatzes zu Gesicht; auch er hat die Lösung ganz anderer Fragen im $\Lambda$ uge und theilt seine Versuche in zu ungenauer Weise mit, als dass für die Ophthalmogic ein sicherer Schluss aus ihncn gezogen werden könnte. --

Bei moinen eigenen Untersuchungen glaubte ich mir mein Viel so eng als möglich stecken zu müssen und beabsichtigte nur die Veränderungen ter Linse in Folge von Reclination und Ibiscision zu studiren; dabei wurde ich aber allmälig zu weit schwierigeren Verhältnissen geführt. Die Lntersuchungsmethode, welcher ich nach einigem l'robiren inmer folgte, war die, dass ich das frische Auge durch einen $\Lambda$ cquatorialschnitt öffnete, alle Gewebe frisch untersuchte, dann das Auge in eine sehr schwache Lösung von doppelt chromsaurem Kali legte und nun in den folgenden Tagen die Lntersuchung vervollständigte. Die von Schweigger*) befolgte Methode scheint mir den Nachtheil zu haben, dass sie den Vorwurf künstlicher 'Trennung und Erzeugung von Kunstproducten in der Retina nicht verhiitet, besonders aber hindert sie die Entersuchung des Fiters.

\section{Folgen der Reclination.}

(Fig. 1 und 2).

1. Fall.

Altes granes Kaninchen. Fs wurde die Re. clination nach miten durch einen Einstich mit einer breiten Nadel $2^{\prime \prime \prime}$ vom äusseren Cornearande gemacht; ein zweiter Einstich mit der Nadel liess in der Pupille keinen Linsenrest melır erkennen. Unmittelbar nach der Operation war keine Veränderung am Auge zu be-

*) Archiv fiir (phthnlmologie VI 1. 141. 
merken. Am $z$ weiten Tage war die linse wieder aufgestiegen und verlegte das Pupillargebiet, sie erschien diffus weisslich getrubt. Am fünften 'Tage ging ich mit der Nadel abermals ein und bewegte die getrubte Linse nach unten, doch wurde die Pupille nicht ganz frei. Am 6. wareu feine radiare Streifen in der sonst ungeänderten Trubung zu sehen. Es erschienen dann in den folgenden Tagen unregelmässige Streifen und Formen an der reclinirten Masse, welche ziemlich glänzend und gelblich aussah, ja einmal schien es, als legte sich eine weisse faltige Membran vor dieselbe. Am 15. Tage fanden sich neben der melır nach hinten befindlichen trüben Masse noch einzelne blendend weisse Streifen und Flecken in den vorderen Partien ohne bestimmte Zeichnung; die radiüren Streifen waren verschwunden. Am 24. Tage war der Befund folgender die Trübung ist weiss und scheint schleierartig den unteren Theil des Augenhintergrundes zu verdecken; der mittlere Theil der 'Trübung, weleher weit vom $\mathrm{Pu}$ pillargebiete gegen den llintergrund liegt, stellt eine runde Scheibe dar, an welcher hier und da Winkel hervor - und zuriicktreten, sie ist gesättigt weissgrau gefärbt mit undeutlichen Streifen. Am Boden vor dieser Scheibe liegt eine blendend weisse Masse, welche eine Zeichnung in graden winklichen Strichen zeigt, wie von Falten oder Streifen, sie muss daher eine ungleiche Oberfläche haben. I) seitlichen und oberen Partien des Augenhintergrundes sind von einer matten Trubung verdeckt; sie theilen bei durchfallendem Lichte derselben eine leicht gelbröthliche Firbung mit, von Jetina- und Chorioideagefässen ist nichts zu erkennen. Für jene scheinende Masse vor der reklinirten Linse wusste ich keine Erklärnng. So blieb der Zustand ohne Aenderung bis zum 40. Tage, an welchem die Exstirpation vorgenommen wurde.

Sectionsbefund. Der Glaskörper war etwas trübe und hatte seine gallertige Cohärenz fast ibberall verloren. Am Bodeu der Glaskörperhöhle lag die Linse in mehreren Flocken, mehr nach hinten ein grosser runder Flock, vor ihm mehrere kleine unregelmässig geformte, alle waren weisslichgetruibt. Am consistenteren 
Theile des Glaskörpers in der Mitte der Höhle zog sich eine höchst feine, an manchen Stellen weisslich punctirte, sonst glashelle Membran, von der Chorioidea weit abstehend; sie war nach vorne an der Zomula befestigt. Die Retina hatte sich hinter ihr in zwei runde Stränge aufgerollt, welche vou der Sehnervenpapille entgegengesetzt in den seitlichen Richtungen verliefen; die seitlichen Bilndel doppelt contourirter Nervenfasern hatten den Drehungspunkt gregeben. Die Linsenkapsel war hinten nul vorn gesprengt, die eingerollten Zipfel lagen an der unversehrten seitlichen Insertion. ... In der (ilaskïrpertlüssigkeit schwammen grosse rundliche \%ellen, 0,008 - $0,014^{\prime \prime \prime}$ gross, sie waren glashell, aber fast alle mehr oder weniger mit Fett gefüllt, jede cnthielt einen grossen Kern mu Kernkörperchen. Diese Zellen sassen jener feinen abgelösten Membran als ein ein einfaches Epithel auf; zeigten aber an ihr nur wenige Fettkörperchen dicht um den Kern. Die Membran selbst war vïllig structurlos und so dïnn, dass sie hauptsächlich nur durch Faltung sichtbar wurde und durch diese einen scheinbar fasrigen Bau vortiuschte. Es war also die hyaloidea, an welcher noch hier und da cinzehne Reste der Retina hafteten und jene weisslichen Punkte bildeten. - Die Linsenkapsel war ansser der (Continuitätstrennung völlig ungeändert, sowohl die vordere als die hintere glashell und ohme jede strnitur; iberall lag an der vorderen Wand sehr selion erhaltenes P'flasterepithel, dessen Zellen um ein I rittel kleincr als die der Hyaloiden waren. Nur in selur wonigen dieser 'Zellen lagen um den länglichen Kern cinige dunkele Fettkörnchen. In den Winkelı der Kapsel fanden sich iiberall in ziemlicher Menge Linsenfasern der Corticalis von normaler Breite und Durchsichtigkeit. -. Dic einzelnen Stiicke der reclinirten Linse nahmen zusammen ein nicht unbeträchtlich verkleinertes Volumen gegen die normale Linse ein; die kleineren Stïcke bildeten zusammen die Corticalis, wáhrend der Kerı cohärent geblieben war. Die Fasern der Corticalis waren etwa drei Viertel so schmal, als normal, ihre Farbe war leicht gelblich, undurchsichtig; die Contouren waren nicht scharf, er- 
schienen briichig, zuweilen selbst ganz fehlend. In Essigsäure traten die Contouren wieder uberall hervor, waren aber bald hierher, bald dahin gebogen, ohne dass beide Seiten dabei gleiche Richtung verfolgt hätten; dabei wurden dic Fasern wieder durchsichtig und etwas breiter. Die Fasern hingen in grossen Schollen zusammen, welche ziemlich durcheinander geworfen waren; in der Mitte der Stiicke fanden sich noch völlig ungeänderte Fasern, nur die Contouren hatten ihre Glätte verloren. Die Fasern des Kerus erschienen weniger verändert, sie waren durchsichtig, hatten sehr markirte, rauhe, brüchige Contouren, welche in Essigsäure ganz glatt, aber nicht durchsichtig wurden, sondern leicht punctirt blieben. - Der Retina lagen viele verfettete Zellen vom Hyaloideaepithel an; die Elemente derselben isolirten sich sehr leicht. Stäbchen und Körnerschicht zeigten keine Aenderung; der Inhalt vieler Nervenzellen war aber nicht homogen, leicht granulirt, sondern in kleine, scharf contourirte, glänzende Kömchen aufgelöst, und hier und da fanden sich in den Radialfasern dieselben Körnchen entweder vereinzelt oder in kleinen Gruppen. Der Grad dieser fettigen Degeneration war in den einzelnen Zellen sebr verschieden. In den dunkelcontourirten Nervenfasern der seitlichen Stränge war das Mark geronnen und bildete, wie gewöhnlich breitere und schmalere Ausbuchtungen. Chorioidea und Iris waren völlig normal. -

\section{Fall.}

An einem gefleckten, jungen Kaninchen wurde die Reclination gemacht und zwar ohne Eröffnung der vorderen Kapsel. Am 2. Tage liess sich ein schräger getribter Strich von einer Seite der Linse zur anderen erkennen, die itbrigen Theile waren völlig durchsichtig. Am 5. verdeckte eine Trübung dicht hinter der Pupille den Augenhintergrnnd, sie war aber durchaus nicht gleichmässig. Am 30. waren in der Trübung viele radiäre Streifen zu bemerken, sonst blieben die Verhältnisse gleich. Am 39. Tage wurde das Auge exstirpirt.

Sectionsbefund. Die Retina liegt der Chorioidea 
iiberall an, der Glaskörper ist flüssig und trïbe. Die Linse ist in zwei Theile getheilt, der eime besteht aus durchsichtigem Gewebe und hat dic äussere Form der Linse bewahrt bis auf die hintere Fläche, in dieser liegt nach hinten und unten der zweite Theil der Linse, welcher mattweiss getrübt ist. Die Oberfläche dieses letzteren ist uneben, gerissen. Nach beiden Seiten hin ziehen sich von der hinteren Kapsel zur Zonula zwei schmale crhabene Stränge. -- Retina und Chorioidea liessen in ihrem mikroskopischen Ban keine Veränderungen bemerken, die Hyaloidea lag der Retina überall an, die Epithelschicht der Hyaloidea war an den meisten Stellen erhalten und nur wenige Zellen enthielten Fettkörnchen. Auch im Glaskörper schwammen nur einzelne verfettete Epithelien mit deutlichen Kernen. Die schmalen Streifen, welche von der Zonula zur hinteren Kapsel liefen, bestanden aus einer structurlosen Membran und einigen verfetteten rundlichen Zellen, wahrscheinlich Epithelien. Der durchsichtige vordere Theil der Linse enthielt die Kapsel und den grössten Theil der Corticalis; die Fasern waren völlig durchsichtig, glänzend, mit glatten Contouren; die Kerne waren sehr schön in ihnen zu sehen, doch die Fasern so schwer von einander zu isoliren, dass ich nicht zur Entscheidung kommen komnte, ob nur einer oder mehrere Kerne zu einer Faser gelı̈̈rten. In der hinteren Kapsel war ein grosses Joch, durch welches der getrïbte Linsentheil in den Glaskörper hineinragte; beide Theile waren scharf von cinander getrennt. Das Gewebe der hinteren Kapsel zeigte keine Structur, war völlig glashell; nur um den Riss lag sie in Falten und war von einer durchsiclitigen, glänzenden, dunkelbegrenzten Masse bedeckt, welche auch nach Zusatz von Reagentien ohne Structur blieb, demnach für Inhalt von Linsenfasern zu erklären war. Die getrübte Linsenpartie wurde vom Kern und wenigen Fasern der Corticalis gebildet; alle Fasern waren sehr eingeschrumpft der Breite nach; an manchen Stellen waren die Contouren derselben so undeutlich geworden, dass sie erst auf Anwendung von Reagentien hervortraten, an anderen waren die Contouren nur unbestimmt, die Fasern 
hatten die Durchsichtigkeit und den Glanz verloren und schienen mit feineu und groben Punkten übersät; in Essigsäure lösten sich diese Punkte; die Fasern wurden durchsichtiger, die Contouren bestimmter und bis auf kleine Unterbrechungen grade. An einigen Stellen traten die Fasern auf Zusatz von absolutem Alkohol rasch und klar hervor. Alle Fasern brachen sehr leicht der Quere nach, doch war eine Querstreifung nirgends zu sehen. Im äussern Umfang der getriubten Masse begegnete man noch häufig jeuer dunkelglänzenden amorphen Masse, wie an den Zipfeln des Kapselloches; sie bildete unregelmässige Schollen mit Ilöckern, zum Theil war sie dunkel punktirt. Für die radiäre Streifung liess sich koin anatomischer Grund finden.

\section{Fall.}

Bei einem jungen, gefleckten Kaninchen machte ich die Reclinatiôn; nach dem Einstich in die Linse ging die Nadel anch durch die Iris hindurch, wurde aber wieder zurïckgezogen und hinter der vorderen Capsel heraufgeführt. Am 6. Tage war die enge Pupille durch eine weisslich getribte Masse verlegt, die Iris schien unverändert zu sein. Das Auge wurde exstirpirt. -

Sectionsbefund: Der Glaskörper hatte ziemlich normale Consistenz, Chorioidea, Retina und Hyaloidea befanden sich in inniger Beriihrung. Ebenso wie in dem vorigen Falle ragte aus einem völlig durchsichtigen, die peripherische Form bewahrenden Theile der Linse ein getrübter, unregelmässig geformter Theil hervor, welcher etwa die Hälfte des Linsenvolumens betrug; er lag nach hinten und unten zur Hälfte im Glaskörper, zur Hälfte noch innerhalb der Kapsel, berührte die Augenwände nirgends. Von der Zonula ging an der einen Seite ein fciner durchsichtiger Strang zur hinteren Kapsel, etwas erhaben uber die übrige Zonula. Vor der Linse in der Mitte der Pupille lag ein Stecknadelkopf grosser, stark weisslich getrübter Fleck. -

Im Glaskörper befanden sich einige Glaskörperepithelien mit vereinzelten Fettkörnchen um den Kern. Chorioidea und Retina waren normal. Der Strang von der Zonula zur hinteren Kapsel bestand ans einer 
structurlosen Membran und einem uuregelmässigen verfetteten Fipithel, musste also als theilweise Loslösung der \%onula aufgefasst werden. Der getrülite Theil der linse hatte eine sehr weiche Consistenz, zerfiel leicht in kleine 'Theilchen, eine Erscheinung, welche von der Neigung der Fasern, quer abzureissen, abhing. Die Fasern waren im Breitendurchmesser etwas geschrumpft, ibre Contouren nicht mehr ganz gradlinigt, sie hatten aber ihren durchsichtigen Glanz bewahrt. An der Oberfläche dieses 'Theiles, sowie anf' den Kapselzipfeln fand sich vielfach jene glänzende, scharf contourirte, amorphe Masse, welehe als ausgetlossener Faserinhalt anzusehen ist. Wic Kapsel hatte mit Ausuahme des Loches in hinteren 'Theile ilıre f'orm bewahrt; ihre Structur, sowie die der ihr anhängenden Corticalfaseru war völlig. ungeändert; in der vorderen Capsel war ein Loch nicht zu bemerken. Die kleine getrilbte Masse vor ihr bestand ans Gorticalisfasem, wche bei der Reclination in Folge der Kapselverwundung in den humor alueus getroten waren. Die Fasern hatten an Breite sehr wesentlich verloren, sie waren im höchsten (trade briichig und sahen wie mit groben Staubtheilchen bestrent aus, ilsre Contouren waren duskel und abgrerissen: in Alkohol wurden die Contouren nicht deut. licher, in Essigsäure lösten sich die Fasern gleich auf. Hinter dieser Masse fand sich doch das Fpithel der vorderen Kapsel etwas verändert, zwischen den normalen, ziemlich sechseckigen Zellen desselben mit grossen Kernen fanden sich einzelne, deren Membranen durch einen durchsichtig - glänzenden Inhalt bedeutend aufgebläht, eine runde Form angenommen hatten; der Kern lag unverändert in der Mitte, so schien die Kapselwunde doch nicht ohne Folgen geblieben zu sein.

In allen drei Fällen sollte die Reclination so gemacht. werden, dass die Linse ohne Verletzung der vorderen Capsel in den hinteren Augenabschnitt gebracht werde; es gelang dies nur im ersten Falle; in den beiden anderen, welche junge Kaninchen betrafen, gelang die Reclination gar nicht und führte nur zur Zerreissung der Linse mit geringer Dislocation der mittleren Partie. Die 
Aehnlichkeit der Fälle beschränkt sich daher auf das Verhalten der losgerissenen Linsentheile und der Kapsel mit den an ihr hängengebliebenen Fasern. In allen drei Fällen trat eine 'Trübung der abgetremnten Linsentheile ein, freilich in den beiden letzten Fällen in weit geringerem Masse, als im ersten. Fs stimmt dies genau mit den Resultaten uberein, welche Die terich erhielt (pag. 67 l. c.). Er suchte von der Hornhaut aus die Depression der Linse zu machen und da er nichts über das Verhalten der Kapsel angiebt, ist wohl anzunehmeu, dass er die Linse aus der Kapsel zu dislociren suchte. In elf Fällen erhielt er nur dreimal keine Trübung der Linse und in diesen drei Fällen ist die Operation, wic es scheint, sehr unvollkommen ausgeführt gewesen.

Schon die Cohäsionstrennung der Linse musste die Durchsichtigkeit vernichten, da nun nicht mehr glatte, sondern rauhe, gerissene Obertlächen vorhanden waren; dann aber bildeten sich anatomische Veränderungen. Dic Linsenfasern schrumpften ein, brachen leicht der Quere nach, verloren ihren Glanz und Durchsichtigkeit; die sonst so scharfen Contouren waren unterbrochen, ihr Inhalt hatte chemische Umsetzungen erfahren, so dass sich punctförmige Körperchen in ihm gebildet hatten. Diese Verwandlung des Inhaltes ist wahrscheinlich für das Wesentliche anzusehen, da sich die ührigen Frscheinungeu sehr leicht auf sic zurückführen lassen. Durch sic verloren Membran und Inhalt ihre Cohäsion, die Membranen ihre Glätte, die Faser ihren Glanz. Diese Pünktchen waren in Essigsäure löslich und sind daher nicht als Folgen fettiger Degeneration aufzufassen; nach ihrer Lösung wurden die Fasern wieder glatt und glänzend. Dieser Prozess, welcher als Einschrumpfung durch Umwandlung des Inhaltes bezeichnet werden kann, war natürlich in der Linse, welche frei in Glaskörper lag, am weitesten vorgeschritten und hatte zur Trennung geführt, 
der derbe Kern war zusammenhängend geblieben, dic Cortialis in mehrere Stücke zerfallen. An den Randtheilen aller Stücke, sowie an den Zipfeln der Kapsel, bildeten ausgeflossene Inhaltsportionen der Fasern glänzende, unregelmässige Klumpen ohne jede Structur. ---

Die Kapsel war in allen Fällen an ihrem Orte geblieben, natürlich an der hinteren Wand gerissen. Die structurlose Membran der Kapsel zeigte keine Veränderung und ebenso das Epithel der vorderen Kapselwand, nur in dem dritten Falle, in welchem ein Stich durch die nicht gesprengte Kapsel ging, liess sie eine Vergrösserung einzelner Zellen erkennen, welche durch cine blosse Vermehrung des Inhaltes hervorgerufen war. In allen Fällen hingen an der hintern Wand der Kapsel und besonders in den peripherischen Theilen grosse Mengen der Corticalis, sie waren in ihrem mikroskopischen Bau auch gar nicht verändert, die Fasern durchsichtig, glatt, die Korne rund, der allmälige Uebergans des Kapselepithels in kleine Linsenfasern liess sich sehr genau verfolgen. Fs sprechen diese Beobachtungen. wic mir scheint, sehr dafür, dass das Kapselepithel die Frnährung der Linse vermittelt. Da nun die ihm anliegenlen liasern nach Reclinationen des Kerns unverändert bleiben und durch dic mikroskopische Untersuchung erwiesen ist, dass von lem Fpithel die Neubildung der Fasern ausgcht, liesse sich mit Fug und Recht die Frage aufstellen: kann eine Regeneration der Linse nach Reclinationen geschehen und in welcher Weise?

In den beiden letzten Fällen gingen einzelne abgehobene Stränge von der Zonula nach der hintern Kapsel, im ersten war die hyaloidea von der Retina abgelöst, ich vermuthe, dass die ersteren Veränderungen Anfänge der Ablösung sind, ohne freilich den Zusammenhang genau nachweisen zn können. 
In allen Fällen fand sich der Glaskörper trübe und Hlüssig, er enthielt bald mehr, bald weniger grosse durchsichtige Zellen in der Flüssigkeit suspendirt. Fs waren platte Epithelialzellen mit grossem runden Kern, um welchen herum dunkle runde Körnchen lagen. (Fig. 2.) Ihr Ursprung war ohne Frage in dem Epithel des Glaskörpers zu suchen. Dies Fpithel der Hyaloidea ist entschieden mit Unrecht von Kölliker und nach ihm von allen neueren Autoren gelengnet. Finkbeiner*) hat dasselbe völlig richtig beschrieben und abgebildet; es besteht aus ganz glashellen grossen Plattenepithelien, welche ästig fest in einander gefügt sind, so dass sie einzeln gesehen ästigen Zellen ähnlich sehen; die Zellen haben die Grösse von $0,008-0,016^{\prime \prime \prime}$ und enthalten stets einen sehr grossen, hellen Kern mit einem oder zwei Kernkörperchen. Es ist eine \%ellenlage, welche der völlig structurlosen Membran der Hyaloiden aufliegt. Die Zellen sind im normalen $\Lambda$ uge schr leicht zu übersehen, die pathologischen Veränderungen dagegen Jassen sie an frischen Augen jedesmal ohne Zweifel erkennen und muss ich den Werth dieser positiven Beobachtung jeder negativen gegenüber behaupten. - Sobald der Glaskörper Veränderungen eingegangen ist, findet sich nach meinen Untersuchungen jedesmal das Epithel der Hyaloidea verändert und bin ich dadurch bestimmt, die Umwandlung des Epithels für die Ursache der Consistenzveränderungen des Glaskörpers zu halten. Die Zellen lassen immer nur einen Weg der Entartung erkennen und dieser liegt in den drei Reclinationsfällen vor. Zuerst erscheinen einzelne kleine, dunkle Körnchen dicht am Kern, diese vermehren sich immer mehr und erfüllen die ganze Zelle zuletzt; der Grund beruht wahrscheinlich in fettiger De-

*) v. Siebold und Källiker, Zeitschrift für wissenschaftliche Zoologie Band VI. 
generation des Zelleninhaltes, während der Kern unverändert bleibt. Es verwandelt sich die Zelle so in eine runde Fettkörnchenzelle. Dadurch verlieren die Zellen ihre Cohäsion untereinander und mit der Hyaloitea und gerathen auf einem noch näher aufzuklärenden Wege in den Glaskörper.*) Hier schreitet die fettige Degeneration noch weiter und zerstört endlich die Membran der Zelle, wodurch der Kern dann frei im Glaskörper erscheint. In den drei Fällen war die Voränderung verschieden weit vorgeschritten, am weitesten natürlich in dem Falle, bei welchem die Hyaloidea abgelöst war; ein grosser Theil der Epithelien hing immer noch unverändert der Membran an. Diese selbst liess nie die Spur einer Degeneration erkennen. - -

In dem dritten Falle liegt noch ein Vorfall von Linsensubstanz vor nach einer Eröffnung der vorderen Kapsel, ohne dass dieselbe gesprengt wurde. Die Linsenmasse blieb dicht vor der Kapsel liegen und beweist so deutlich, dass der Unterschied des intraoculären Druckes auf die vordere und auf die hintere Kapselwand (oder auch im humor aqueus und im Glaskörper) nur unbeträchtlich ist. Dic Veränderungen dagegen, welche diese vorgefallenen Fasern erlitten, waren vicl bedeutender, als die der reclinirten Theile; trot $\%$ dem, dass der Vorfall erst wenige Tage alt war, zeigte dor Faserinhalt einen sehr hohen Grad jenes Zerfalls in eine krümliche Substanz, zugleich aber hatten die Membranen so bedeutende Umwandlungen erfahren, dass sie in Reagentien nicht deutlicher erschienen, sondern rasch verschwanden. Auf diese Weise wird natürlich der rasche Zerfall und gänzliche Resorption vorgefallener Linsentheile in dem humor aqueus ermöglicht.

*) Die gewöhnliche Ansicht ist, dass das Fpithel der Hyaloidea an der äusseren Seite sitzt. 
Die gemeinschaftlichen Veränderungen beschränken sich also auf die Linse und das Epithel des Glaskörpers, es muss noch eine offene Frage bleiben, ob nicht in der Verflüssigung des Glaskörpers und der Verfettung scines Epithels die ersten Bedingungen zur Ablösung der Hyaloidea und endlich auch der Retina gegeben sind. - In dem ersten Falle war nach der Reclination Ablösung der Retina eingetreten und zwar in einer Weise, wie sie beim Menschen nicht erfolgt. Der Grund dafür lässt sich in dem Bau der Kaninchenretina leicht erkennen, da die zweiästige Ausstrahlung dunkelwandiger Nervenfasern aus der Papille diesen Strängen wahrscheinlich eine solche Festigkeit giebt, dass die losgetrennte Retina sich in zwei Theile scheidend um dieselben aufrollt. Die Anheftungspunkte der Retina an die Zonula waren völlig gelöst; alles dieses lässt mich den Grund der Ablösung in dem Verhalten der Hyaloidea suchen. Die Folgen der noch ziemlich frischen Retinaablösung waren in dem mikroskopischen Verhalten dieser Membran unschwer zu bemerken. Sie bestanden in fettiger Degeneration der Nervenzellen und des Inhaltes der Radialfasern. In Zellen und Fasern sonderten sich Membran und Inhalt; die Membran blieb unverändert und behielt die Form des normalen Gebildes bei, der Inhalt zerfiel in Partikelchen, welche sehr glänzten, von sehr verschiedener Grösse waren und gegen Essigsäure völlig resistent; daneben waren natürlich die Kerne der Zellen wohl erhalten. Dass ich diese Veränderung für fettige Degeneration anspreche, ist wohl erklärlich; für ein Kunstprodukt ist sie entschieden nicht anzusehen, da an frischen und in chromsaurem Kali aufbewahrten normalen Netzhäuten derlei Gerinnungen nicht vorkommen. Eine Besprechung der Folgerungen, welche sich hieraus für den Bau der Retina ergeben, muss ich bis zur Erklärung der Eiterbildung im Inneren des Auges verschieben, erlaube mir 
nur vorher zu erklären, dass ich der Annahme, welche von Max Schultze*) aufgestellt ist, dass ein 'Theil der Retinaelemente zum Bindgewebe zu stellen sei, mit unberleutenden Modificationcn beistimme, dagegen solchen Uebertreibungen, wic sic $\mathrm{Klebs}{ }^{* *}$ ) andentet, der mit Ausnahme der Nervenfasern und Nervenzellen nur Bindegewebe in der Retina anzunehmen scheint, entgegentreten zu müssen glaube, indem ich mich dabei nicht auf physiologische Theorien, sondern auf anatomische Anschauung stützc. Uebrigens hat, wie ich glaube, Schweigger die Fettentartung der Radialfasern zuerst gesehen, er beschreibt wenigstens in 1 . Hefte des VI. Bandes dieses Archives pag. 153 fettig degenerirte Fasern, welche er freilich, ohne sich bestimmt auszusprechen, zu dem '/wischen-Bindegewebe der Retina rechnet.

Wenn es nun erlaubt ist, nach so wenigen Fällen einige allgemeine Gesichtspunkte zu berühren, so glaube ich folgende Schlüsse ziehen zu können:

1. Reclination der Linse ohne Kapsel ist nur bei tiner gewissen Consistenz der Linse möglich, welche den Linsen junger Thiere abgeht. -

Dieser Satz hat schon immer practische Greltung gehabt, allein den experimentellen Beweis habe ich nirgends finden können. -

2. Die Fasern reclinirter Linsentheile schrumpfen ein, indem der Inhalt resorbtionsfähig zerfällt, die Mombran wahrscheinlich ungeändert bleibt.

3. Dabei verlieren sie ihre seitliche Cohärenz und die reclinirte Linse kann in mehrere Stücke zerfallen.

4. Die Schrumpfung der Linse kann auf die Retina so wirken, dass die Netzhautablösung erfolgt, ohne dass ein Chorioidalleiden besteht; die Verfettung des Hyaloidea-

*) Observationes de penitiori structura retinae.

*) Virclıow. Archiv für photologiselı. Anatomie XIX 3 und 4. 
epithels und Verflüssigung des Glaskörpers mag allerdings eine Stütze der Retina erschüttern.

5. Die Linsentheile, welche in der Kapsel bleiben, unterliegen durchaus keiner Veränderung, sie bleiben völlig durchsichtig und es müssten daraus die grössten Unregelmässigkeiten für den Sehact entspringen, wenn die Sehaxe durch solche Theile gehen könnte.

6. Die Kapsel reclinirter Linsen wird wohl zum grössten Theil aus ausgeflossenem Inhalt der Linsenfasern bestehen.

\section{Folgen der Discision und Verwundungen der vorderen Kapsel.}

1. Fall.

Junges Kaninchen. Fs wurde die Discisionsnadel tief in die Linse eingestochen und sehr ausgiebige Bewegungen in mehreren Richtungen gemacht, das Kammerwasser floss nach der Operation aus. Am 3. Tage fand sich ein viereckiger Capselspalt, aus welchem ein schmaler durchsichtiger Linsenflock bis zur Cornea vorgetreten war; innerhalb des Spaltes schien die Linse gesättigt weiss getrubbt. Am 5. 'Tage war die Wunde viel kleiner geworden, mit ihr war die Linsentribung geschrumpft, der vorgefallene Flock ist sehr schmal geworden, besonders am vorderen Theile. Am 10. Tage war der Linsenvorfall völlig verschwuuden, der Kapselspalt nur noch schlitzförmig, die Linse völlig durchsichtig. Der Streif in der Kapsel verschwand dann iu den nächsten Tagen. Bei der Section am 18. Tage fand sich keine Spur der Kapselwunde und in der Linse durchaus keine Veränderung.

\section{F all.}

Altes geflecktes Kaninchen. Stich durch die Cornea mit einer feinen Discisionsnadel bis tief in die Linse. Die Lirsensubstanz war sehr resistent und nur mulhsam liess sich ein Krelzschnitt machen; einige 
Fasern hafteten an der Nadel. Nach dem Ausziehen der Nadel floss ein Theil des humor aqueus aus; die Pupille verengte sich stark. Am 2. Tage war die Kapsclwunde punktförmig geschlossen, die Kammer vollstäıdig wieder gefiultt. Abermals Discision, aber nur in den oberflächlichen Schichten, es floss nur wenig humor aqueus aus, die Pupille verengte sich wieder. Am 3. Tage waren beide Kapselwunden nur noch an den weissen Einstichspunkten zu erkennen; in der vorderen Kammer befand sich keine Linsensubstanz, in der Linse selbst lagen einige dicke weisse Streifen, volt den Stichpunkten ausgehend. Die Kammer war tief, l'upille etwas verengt. Die Diseision wurde wiederholt mit einem groben Kreuzschnitt und, da am 4. Tage sich keinc Aenderung fand, nun noch zwei tiefe Einstiche in die linsc gemacht. Am 5. Tage war die Cornea ranchig getriibt. Fünf kleine weisse Punkte waren in der Kapsel zu sehen; vor den beiden Punkten, welche den letzten Einstichen entsprachen, hingen zwei kleine cylindrische Flöcke grade nach vorn, sie waren fast völlig durchsichtig. In den folgenden Tagen trübten sich diese Vorfälle von Linsensubstanz etwas, doch senkten sie sich gar nicht, am 9. Tage war der äussere Theil der Iris nach ihnen hin verzogen und ling ihnen fest an. Es wurde dann ein lineïrer Schnitt gemacht und mit dem Daviel'schen Löffel die vorgefallenen Theile ausgezogen, wolchen sic auch in Zusammenlange beim ersten Zuge folgten. Die Masse war durchscheinend getrübt, hing ziemlich fest zusammen und liess sich nur schwer auseinander zupfen. Bei der mikroskopischen Intersuchung fanden sich die Linsenfasern, welche die ganze Masse zusammensetzten, sehr wesentlich verändert. Die best erhaltenen Fasern waren schmaler, die Contouren breiter und sahen wie mit Staub bestreut aus, doch lagen diese mattgranen, höchst feinen 'Theilchen innerhalb der Membranen; an den meisten Stellen bildeten aber diese feinen Partikelchen in langen, mit einander parallelen Linien die Contouren der Fasern, ohne dass eine besondere Membran sichtbar gewesen wäre; an vielen Stellen war einc besondere Faserordnung gar nicht $z \mathfrak{u}$ erkemnen, obgleich 
kein Zerfall dieser Theile bevorstand. Aether hatte durchaus keinen Finfluss auf die feinen Körnchen, dagegen machte sie Essigsäure verschwinden; durch diese wurde das ganze Object klar und nun waren tiberall, wenn auch an manchen Stellen nur durch grosse Aufmerksamkeit, schwache Contouren der Fasernmembranen zu sehen. Dieser Zerfall des Faserinhaltes und wahrscheinlich auch der Membran war also nicht als fettige Degeneration, sondern als Zerfall in Eiweissmolecüle aufzufassen. Ausserdem fanden sich noch einzelne runde Haufen grösserer glänzender Körnchen und in ihrer Nähe kernartige Gebilde, welche jeh als fettig zerfallene Kapselepithelien und ihre Kerne denten muss; diese waren durch den Vorfall der Linsenmasse gewiss vom Kapselrande abgestreift. Dann haftete an der einen Seite einiges Irispigment in Folge der Irisanlagerung.

\section{Fall.}

Junges geflecktes Kaninchen. Fs wurde mit einem Lanzenmesser ein kleiner Schnitt am äusseren Hornhautrande gemacht; beim Fingang mit dem Cystotom in die Wunde zuckte das Thier und es eutstand ein Vorfall des äusseren Iristheiles, welcher abgeschnitlen wurde. Dann wurde mit dem Cystotom die Kapsel ausgiebig geoffnet, es entstand dann ein kleiner Bluterguss im Pupillargebiete. Am 2. 'Tage war' die vordere Kammer wieder gefïllt; die Pupille eng, dahinter eine breite, viereckige, weit klaffende Kapselwunde mit weissen Rändern. Aus dicser war Linsenmasse kegelförmig vorgetreten, sie erschien ungleichmässig getrilbt, entsprang mit breiter Basis aus der Kapselwunde und endete spitz an der Hornhaut. Es war eine zusammenhängende Masse, welche grade vorsprang, ohne jede Senkung. Am 3. 'Tage erfolgte die Erweiterung der' Pupille auf Atropineintröpflung rasch und gleichmässig, die änsseren Theile der Linse waren völlig durchsichtig; die scharfe Kapselwunde mass nach ungefihrer Schätzung $2 \mathrm{Mm}$. im Quadrat. Es wurde dam durch einen kleinen lineären Schnitt die vorgetriebene Linsenmasse aus der vorderen Kammer gezogen. Die Ver- 
änderungen der Fasern waren erst sehr gering, sie erschienen durchsichtig, gradlinigt, ihre Cohärenz gross, nur an einigen Stellen war die sonst scharfe Membrancontour fein punktirt. Dann fanden sich viele glänzende Kugeln aus Faserinhalt, deren einige von Blutfarbstoff gelb gefärbt waren. Am 4. Tage war die vordere Kammer noch sehr flach, Bluterguss im $\mathrm{Pu}$ pillargebiete hinderte den Anblick der Linse. Es bildeten sich dann in den nächsten Tagen Conjunctivalgefässe in der Nähe der Hornhantwunden, aus diesen traten Zweige auf die Hornhaut über bis zu den Wunden hin. Am 12, Tage waren die gewulsteten Cornea wundränder geebnet und die Rückbildung der Gefässe schon begonnen. Die Pupille hat sich etwas erweitert, durch den unteren Theil derselben sieht man ungetrübte Linsensubstanz, den mittleren nimmt ein starker Linsenvorfall ein, welcher bis an die Cornea reicht, den oberen verdeckt der sehr geschrumpfte Bluterguss. Am 15. Tage war der Bluterguss fast völlig aufgesogen, in den hinteren Linsenpartien erschienen schwach getrübte Streifen. Der Bulbus wurde exstirpirt.

Sectionsbefund: Der Glaskörper, sowie der ganze hintere Augenabschnitt zeigte durchaus keine Abnormität. Die Linse hatte ihre runde Form völlig bewahrt. Die processus ciliares liegen dem Linsenrande iiberall an. In den hinteren Linsenpartien befanden sich einzelne, ungleich lange und breite Streifen. Ans der vorderen Kapselwunde war cine breite Linsenmasse vorgefallen, welche vorn fest mit der Cornea und fast ïberall mit dem Pupillarrande der Iris verwachsen war. Sie war getrübt und hing nach hinten mit dem Linsenkern zusammen, welcher bei künstlicher Trennung der Linse zum grössten Theil an ihr hängen blieb. Nach oben lag neben der Masse ein kleiner Rest des Blıt ergusses. Die vordere Kammer war sehr flach.

Bei der mikroskopischen Untersuchung ergaben sich nun folgende Veränderungen. In den durchsichtigen Theilen der Linse lagen ganz normale Corticalisfasern, die getrübten Streifen in ihnen bestanden aus schmaleren, wenig glänzenden, nicht scharf contourirten Fasern. Zwischen den Contouren derselben befanden 
sich kleine dunkle $\mathbf{Z}$ wischenräume, die Contouren waren ganz unregelmässig gezackt. In den rückgebliebenen Kerntheilen waren die Fasern weit mehr verändert und zwar in mehreren Richtungen; die grössere Menge der Fasern war schmuler geworden, auch wenn man den kleinen dunklen Zwischenraum, welcher zwischen den einzelnen Fasern lag, zu jeder hinzurechnete, die Fasern hatten dabei den Glanz verloren und sahen wie mit Staub bestreut aus, an manchen Fasern schienen die Contouren nur aus diesen feinen Punktchen z1sammengesetzt zu sein, welche in Essigsäure gelöst wurden; an anderen Fasern waren die Contouren nur zackig geworden, wodurch die Faser ihren Glanz theilweise einbüsste, und weniger fest mit den übrigeu zusammenhing. Die Kapsel war überall durchsichtig, ihr Epithel aus schönen durchsichtigen Zellen zusammengesetzt, ihre eingerollten Zipfel lagen um die vorgefallenen Linsentheile herum. Diese Theile hatten eine weissliche, undurchsichtige Farbe, glänzten aber etwas; an der Stelle, wo der Bluterguss erfolgt war, erschien die Farbe gelblichroth. Der anhängende Kern hatte ähnliche Veränderungen erlitten, wie die zurückgebliebenen Theile desselben, und von hier bis zur Cornea hin erschienen nun Stufen weiterer Veränderungen. In der Masse der Fasern nahm die punktförmige Trübung der Contouren mehr und mehr zu, die Contouren wurden in andern gröber gezackt und an manchen Stellen schienen sie ganz zu feblen. Näher nach der Descemet'schen Membran verlor die getriibte Masse jedes Kennzeichen eines Gewebes, Linsenfasern waren nicht mehr zu erkennen; es war eine mattglänzende, gelblich gefärbte, amorphe Masse ohne jede Reaction gegen Essigsäure, nur einzelne runde Kerne und wenige Körnchenkugeln waren in ihr zerstreut. Diese Kerne lagen auch und in grösserer Menge in den vorgefallenen Fasern, waren also Faserkerne; einzelne stimmten auch mit den Kernen des Epithels uberein und lagen frei. Der allmälige Uebergang dcs Linsenkerns in jene amorphe Masse liess keinen Zweifel übrig, dass die letztere aus umgewandelten Fasern bestand. - Die Iris lag in grossem Umfange dem Vorfall an und zwar 
durch das Pigmentepithel, welches bei der ziemlich leichten Trennung zum Theil an dem Vorfall hängen blieb. Das Gewebe der Iris am Pupillarrande zeigte keine Abweichung. Weit fester hing die Spitze des Vorfalls an der hinteren Wand der Cornea; nur mit Gewalt und so dass die äusserste Spitze hängen blieb, liessen sie sich trennen. Das Epithel der Descemet'schen Membran war hier völlig erhalten, die Zellen waren durchsichtig und manche enthielten zwei Kerne; die structurlose Schicht und die anliegenden Theile der Cornea selbst waren völlig ungeändert.

An der oberen Seite der Hornhant, entsprechend dem letzten linearen Schnitte, bestand in grosser Ausdehnung eine feste Anlagerung der Cornea, Iris und vorderen Kapsel, so dass sie nur mit Gewalt getrenut werden konnten, doch war ein Uebergang der Gewebe durchaus nicht zu bemerken. Die vordere Kapsel lag dem Uveapigment fest an und ebenso die Tpithelien der Descemet'schen Membran dem Epithel der Iris, es waren aber die Hornbautkörperchen in den tiefer liegenden Schichten und die Bindegewebskörperchen der Iris vergrössert und zwar durch Massenzunahme der Kerne, ohne dass aber irgendwelche Theilungsvorgänge zu sehen gewesen wären.

\section{Fall.}

Junges geflecktes Kaninchen. Durch einen lineären Hornhantschnitt wurde das Cystotom in die vordere Kammel gefithrt, tief in die Linse gesenkt, aber die vordere Kapsel nur in geringer Ausdehnung zerrissen. Am zweiten Tage fand sich die Wunde der Kapsel klein, quadratisch geöffnet und aus ibr war ein breiter Cylinder unregelmässig getrübter, im Ganzen ziemlich durchsichtiger Linsensubstanz hinausgetreten, reichte aber nicht bis zur Hornhaut. Am dritten Tage war der äussere Theil der Pupille nach dem Vorfall verzogen; durch Atropin, welches die übrige Pupille rasch erweiterte, wurde der Zusammenhang des Vorfalls und der Iris nicht gelöst. Am 5. machte ich mit der Discisionsnadel in den inneren Theil der Linse 
einen ausgiebigen Kreuzschnitt, ohne den Vorfall zu berühren. Am 6. war an der Stelle, wo ich mit der Discisionsnadel eingegangen war, eine punktförmige Oeffinung in der Kapsel, durch diese ein schmaler Cylinder Linsensubstanz bis zur Cornea vorgefallen und der innere Pupillarrand der Iris schon an ihm adhärent. Das Auge wurde nun zu anderen Versuchen benutzt, es gelang durch Reclination, den breiten Linsenvorfall in den Glaskörper zu legen. Am 44. Tage wurde das Ange exstirpirt. Der schmale Streifen von der Kapsel zur Cornea liess sich von der Iris leicht so trennen, dass einige Pigmentzellen der Uvea an ihm hängen blieben; mit der Cornea hing er aber äusserst fest zusammen. Er bestand aus einer derben, feingranulirten Masse, welche in Essigsäure durchsichtig wurde und keine Streifung erhaltener Linsenfasern zeigte. Die Descemet'sche Membran war mit ihrem Epithel völlig erhalten an der Stelle, wo der Streifen ihr anhing.

\section{Fall.}

Junges Kaninchen. Es wurde die Discision in der Weise gemacht, dass der Einstich in die Llnse ziemlich dicht am oberen Papillarrande lag, und von hier ans, ohne die Iris zu berühren, ein ausgiebiger Kreuzschnitt vollführt. Am 2. Tage war aus der punktförmigen Kapselwunde eine kegelförmige Masse von Linsensubstanz vorgefallen, deren Spitze an der Cornea haftete. Sie war leicht getribt, der obere Pupillarrand der Iris hing mit ihr fest zusammen. Es wurde die Discision mit ausgiebigem Kreuzschnitt am äusseren Rande der Pupille wiederholt. Auch hier war am 3. Tage ein Linsenvorfall bis zur Cornea und festes Anhangen der Iris an denselben entstanden; die Kapselwunde war punktförmig. Am 5. Tage machte ich dann einen tiefen Einstich mit der Discisionsnadel durch die Linse hindurch vom unteren Rande aus und ausgiebige Bewegungen. Am folgenden Tage war an der untern Seite der Linse ein Vorfall und Anlagerung der Iris an denselben zu bemerken. Es bildete sich nun diffuse Trübung der Linse in Folge von Eiterbildung im hinteren Augenabschnitt, die Pupille nahm eine 
dreieckige Form an und wurde immer enger; der untere Linsenvorfall verschwand, die beiden anderen blieben und schien die Iris sich immer mehr der Cornea zll näherı, so dass die Adhäsionen der Iris zuletzt dicht am linteren Cornearande lagen. Bei der Exstirpation des Auges am 16. Tage fand sich vor der vorderen Kapsel kein Eiter; die beiden Adhäsionen hingen der Cornea und Iris fest an, besonders aber der letzteren; die äussere riss übrigens bei einer unvorsichtigen gen Manipulation und konnte daher zur lntersuchung kaun benutzt werden. Das Fpithel der Descemet'schen Membran war unversehrt; die Faserung des Irisgewebes ging unmittelbar in die Adhäsionen uber, die Iriskerne lagen bis zur Cornea hin; der hintere Theil des Vorfalls bestand aus einem völlig amorphen Gewebe ohne jede Structur.

\section{Fall.}

Junges Kaninchen. Es wurde die Discisionsnadel $8 \mathrm{Mm}$. tief dureh die Cornea in die Mitte der Linse gestossen und ausgiebige Bewegungen in allen Riclitungen gemacht. Am 2. Tage fand sich ein viereckiger klaffender Kapselspalt, die Wundränder der Kapsel glänzten stark weiss, aus dern Spalt war cin schmaler, nur wenir getrubter Linsenflock bis zur Cornea vorgetreten. In den folgenden Tagen verkleinerten sich Kapselspalt und Vorfall ziemlich raseh, der Spalt wurde schmal, der Vorfall dunner; endlich seliwand der Vorfall ganz und in der Kapsel blieb nur ein weisser Streif zuriick. Als am 15. Tage die Section gemacht wurde, war von der Capselwunde nichts mehr zu entdecken.

\section{Fall.}

Junges Kaninchen. Es wurde die Discisionsnadel tief in die Mitte der Linse gestossen und in der linse hin und her bewegt. Am 3. 'Tage war aus der kapsclwunde ein breiter Linsenflock bis an die hintere Wand der Comea vorgefallen, der Pupillarrand der Iris von aussen und innen mit ihm verklebt, so dass die P'upille in einen kleineren oberen und cinen grö- 
sseren unteren Kreis getheilt war und die Form einer

8 angenommen hatte. Am 4. Tage war der untere Kreis der Pupille sehr erweitert; die innere Verziehung der Iris hatte sich der Corneawand genähert. Die Linse war diffus getrübt. - Die linse wurde nun zu weiteren Versuchen reclinirt. Bei der Section am 12. Tage hing die vordere Kapsel durch einen langen, ziemlich festen, durchsichtigen Faden mit der Cornea zusammen; der innere Irisrand hing an ihm fest und lag ebenfalls der Cornea an; der Faden war vom Uveapigment schwarz gefärbt. Das Epithel der Descemet'schen Membran war unversehrt, der Faden zeigte einen streifigen Bau und hellgelbe Färbuvg; längliche Kerne, welche öfters zu sehen waren, gehörten der Iris an, deren Gewebe ungeändert war.

Im Ganzen sind diese Versuche nur Wiederholungen derjenigen, welche zuerst von Dieterich und später von Beger angestellt wurden, um die Fntzündbarkeit der Linsenkapsel zu bestimmen, nur war es meine Absicht, die Veränderungen der Linsensubstanz nach verschiedenartigen Verwundungen von der vorderen Seite der Kapsel aus näher zu definiren. Die Resultate der grob-anatomischen Untersuchung, welche jene erhielten, werden durch meine Versuche völlig bestätigt, dagegen bedürfen allerdings ihre mikroskopischen Resultate und die daraus erfolgte Lrklärung nach den jetzigen richtigeren Anschauungen des anatomischen Baues sehr wesentlicher; wenn nicht völliger Aenderung. Sie hatten gefunden, dass die äussere Kapsel auf Verwundungen nicht reagirt, dass ihre Wunden sich olne Weiteres wieder schliessen, wenn nicht vorfallende Linsenmasse dieses verhindert. Bei allen meinen Versuchen blieb die Kapsel völlig ungeändert; die Schnittwunden waren ohne jede Folge, hinterliessen keinen Spalt und wurden niemals sichtbar, so dass also die Ränder wieder einfach sich mit cinander vereinigten. Einfache Stichwunden und die Finstichs- 
punkte der Schneideinstrumente verhielten sich gleich; sie wurden durch vorspringende Linsenmasse auseinander gehalten, und es war an der Stelle ein weisser Fleck in der Kapsel zu sehen, so lange als diese Masse in dem Spalte lag; so wie die Masse resorbirt war, schloss sich dic Oeffnung und der weisse Fleck verschwand. Die Kapsel zeigte dabei nie eine Veränderung der Structur, die weisse Farbe des Spaltes ist also nur auf die veränderten Refractionsverhältnisse zurïckzuführen. Dagegen erreicht man durch die Dilaceration mit dem Cystotome grosse klaffende .Wunden der Kapsel, die Grösse der Wunde richtet sich aber nur nach der Breite der vorspringenden Linsenmasse, um welche sich die Kapsel fest anlegt. Jer Wundrand der Kapsel erscheint auch hier hellweiss und stark glänzend. Mit der Schrumpfung der vorgefallenen Masse geht dann Hand in Hand der Verschluss des Kapselloches, die Ränder legen sich aneinander, verlicren damit ihre weisse Farbe; die Wunde wird zuletzt spaltförmig und verschwindet ohne jede Narbe. Weder die structurlose Membran, noch das Epithel dcr Capsel lassen während und nach diesen Vorgängen irgend welche Veränterung erkennen Offenbar liegt also die Kapsel den vorderen Linsenschichten so fest auf, dass an ein Zurückweichen derselben nach Verwundungen nicht zu denken ist, es hängt das Klaffen der Wunde nur von der Grösse des Linsenvorfalles $a b$, dic Wundränder der Kapsel legen sich, wenn kein hindernder Körper zwischen ihnen liegt, einfach aneinander und haften so fest, wie vor der Continuitätstrennung. Die Verbindung erfolgt ganz in derselben Weise, wenn längere Zeit seit der Trennung verstrichen ist.

Hierin ist auch der Grund zu suchen, dass die Verwundungen der vorderen Kapsel so sehr geringfügigen Einfluss auf dic Linse selbst üben. Dieterich und Beger fanden nur äusserst selten Verdunkelungen der 
Linse, dagegen bemerkten sic jedesmal ans der Oeffnung der Kapsel eine feine durchsichtige llocke vorgefallen, welche von beiden für verdichteter humor Morgagni erklärt wurde; Beger bildet diese l'locke in Antmons Archiv für dic Ophthalnologie Band III 'Tab. III Fig. 1 und 2 sehr schön ab und erwähnt, dass sic bis zur Cornea reiche. 1)a der humor Morgagni als Leichenproduct anzusehen ist, so bleiben ihre Erklärungsversuche natürlich nicht mehr stichhaltig. --. lis wirkt, sowic durch die Oeffnung der Cornea der humor aqueus ganz oder zum 'Theil ausgeflossen ist und nun eine DruckDifferenz zwischen vorderer Kammer und Glaskörper entstanden, diese I)ifferenz natürlich auf die ganze vordere Kapsel; da aber die übrigen Theile Widerstand leisten, so kann nur durch dic gemachte Oeffnung ein Theil der Linse herausgesprengt werden. Diese vorgetriebene Masse hat immer die form eines Kígels, dessen Basis an der Kapsel die Breite des Kapselspaltes einnimmt, dessen feine Spitze bei schnalen Wunden immer an der Cornea haftet, bei breiteren sic aber oft nicht erreicht; natürlich ist dies auch von der Grösse des einwirkenden Druckes und dadurch wieder von der Menge des ausgeflossenen humor aqueus abhängig. (jleich nach der Operation ist der Kegel nicht zu sehen, er wird erst nach einigen Stunden sichtbar und erscheint dann matt getrübt; dass er aber im Augenblicke der Operation entsteht, darüber kann wohl kein \%weifel sein.

Nach der mikroskopischen lntersuchung besteht die vorgetriebene Masse nur aus Linsenfasern. deren unregelmïssige Ecken in Folge der Trennung von den übrigen Fasern und ihre Imbition mit humor aqueus wahrscheinlich die geringe 'Triibung' und das Sichtbarwerden bedingen. Dann aber unterliegen die Fasern rasch chemischen Veränderungen, welche schon im dritten Falle der Reclination vorlagen und schnell die liesorption eines 
Theiles der Fasern einleitet. Die Fasern verlieren ihren Glanz, werden undurchsichtig, erst fein, dann grob punktirt; es scheiden sich also Partikelchen des Faserinhaltes aus, welche in Essigsäure löslich sind. Die Menge des Inhaltes scheint dabei vermindert zu werden, denn die Membran wird runzligt und unregelmässig gezackt, zuletzt geht, wahrscheinlich durch Resorption des zerfallenen Inhalts, die ganze Masse in ein dichtes streifiges Gewebe über, welches man nach allem wohl für zurückgebliebene Membranen der Fasern halten kann. Wenn der Kegel frei steht, so kann er auch wohl ganz verschwinden; ob dies durch völlige Resorption der Fasern oder auch durch theilweises Zurücktreten in die Kapsel geschieht, ist nicht mit Deutlichkeit zu bestimmen. Es nimmt der Durchmesser des Vorfalls allmälig $a b$, dann schwindet zuerst die schmale Spitze, später die Basis; doch lässt sich der Vorgang auf beide Weisen erklären, wenn auch die Beobachtung mehr für die Resorption spricht. Dieterich giebt an, dass die Flocken in 10 bis 18 Tagen wieder völlig verschwinden können; im Fall 6. war nach 15 Tagen keine Spur des Linsenvorfalles zu bemerken. - Der Zerfall des Faserinhaltes, welcher sicher zu verfolgen ist, kann übrigens durchaus nicht als fettige Degeneration bezeichnet werden, da die Theilchen in lissigsäure löslich und also zu den Proteinverbindungen zu rechnen sind; wahrscheinlich ist es wohl, dass sie in den humor aqueus gerathen und hier weiteren Veränderungen anheimfallen, in den Fasern selbst konnte ich keine anderen entdecken.

Wenn der Linsenvorfall in der Nähe des Randes der Pupille liegt, so sieht man immer nach einem oder zwei Tagen eine Verklebung des Irisrandes mit ihm und eine Verzichung der Pupille dahin eintreten; ist der Vorfall sehr breit, so kann diese Verklebung beide gegenüberliegenden Pupillenränder treffen und die Pupille dadurch 
in zwei Kreise getheilt, nimmt die Form einer 8 an. Die Anlagerung der Iris geschieht immer mit dem Pigment der Uvea, so dass bei künstlichen Trennungen immer Zellen der Uvea an dem Linsenflock hängen bleiben. An dem Strange rutscht dann die Iris allmälig nach vorn gegen die Cornea hin, bis sie dieser ganz anlagert; wodurch aber dieses Rutschen bewirkt wird, ob durch das Schrumpfen des Fadens oder sonst aus welcher Ursache, bin ich nicht im Stande anzugeben. Es ist aber bei dem Anhangen des Fadens an der Cornea ein sehr regelmässiges Ereigniss. Während dieser Bewegung bleiben an dem Faden überall Pigmentklumpen und Pigmentzellen aus der Uvea hängen, so dass der Faden zuletzt ganz schwarz erscheint. Auf welche Weise die Anlagerung der Iris an den Linsenvorfall hervorgerufen wird, lässt sich ebenfalls nicht mit völliger Gewissheit bestimmen, doch giebt der Umstand, dass die Linsenvorfälle im mittleren Pupillargebiete keine solche Verwachsungen bedingen, vielleicht Grund zu der Vermuthung, dass die Bewegungen der Pupille die Veranlassung zur Anlagerung beider Theile geben. Die Adhäsion ist aber von vornherein so innig, dass die Erweiterung der Pupille sie nicht mehr zu trennen vermag, selbst wenn einmal eine starke Atropinlösung (gr. IV in unc. j aq.) eingetröpfelt wird. In dem Gewebe der Iris habe ich nie Veränderungen bemerken können, sie lagerte auch nach mehreren Wochen sowohl dem Vorfall, als der Cornea einfach an, doch machte sie, je mehr die Linsenfasern schrumpften, einen um so grösseren Theil der Verbindung aus; die Kerne der Iris zeigten durchaus keine Vermehrung. --

Die vorgetriebene Linsenmasse erreichte in den meisten Fällen, bei kleinen Kapselwunden sogar stets die hintere Wand der Hornhaut und war schon nach wenigen Tagen nur mit Gewalt von ihr zu trennen und dann auch nur so, dass entweder Epithel der Descemet- 
schen Membran an der Linsenmasse oder Linsenfasern an der Descemet'schen Membran hängen blieben. Pathologische Veränderungen der Descemet'schen Membran oder der hinteren Schichten der Hornhaut waren niemals zu finden; überall war die structurlose Membran und das Epithel wohl erhalten und es bestand auch hier nur eine einfache Verklebung beider Theile, deren Festigkeit allerdings Erstaunen erregen kann. Auch nach lïngerer Zeit fanden sich immer dieselben Verhältnisse.

Diese Versuche liefern den experimentellen Beweis für das Zustandekommen und die Verhältnisse der Synechien, welcher vielleicht doch noch Werth hat, wenn auch die practische Erfahrung ohne deutliches Aussprechen dasselbe schon gefühlt hat. Es scheint danach, sowie eine fremde Substanz der vorderen Kapsel auflagert, die Bildung der hinteren Synechie jedesmal zu erfolgen, diese fremde Substanz wird natürlich in den meisten Fällen durch von der Iris selbst geliefertes Exsudat gebildet. Die Anlagerung geschieht durch die Pigmentzellen der Uvea und, ohne dass je cin Uebergang der Gewebe in einander stattfindet, erreicht sie eine sehr bedeutende Festigkeit. Dadurch dass solche fremde Massen an die hintere Wand der Cornea anstossen, wird dann die Bildung vorderer Synechien vermittelt. Auch beim Menschen habe ich wiederholt, wenn in Folge alter Hornhautgeschwüre die Cornea grosse Substanzverluste erlitten hatte und ausgedehnte feste vordere Synechien bestanden, das Epithel der Descemet schen Membran wohl erhalten gefunden, die structurlose Membran war dann gefaltet und schien im Dickendurchmesser geschrumpft zu sein.

Nur äusserst selten treten nach Linsenverletzungen, wie ausgedehnt sie auch gemacht werden, Verdunkelungen der Linse ein. Dieterich sah sie in 38 Fällen nur einmal, ich in 7 Fällen nur einmal in sehr beschränktem 
Masse. Es ist dies eine Erfahrung, welche auch nach zufälligen Verwundungen gesunder Linsensysteme bei Menschen gemacht wird, und findet seine Begründung wahrscheinlich darin, dass die Einwirkung des humor aqueus auf die Linse durch den engen Verschluss der Kapselwunde und den Vorfall des kleinen Linsentheiles vollständig verhütet wird. Sehr häufig hört man daher von Augenärzten den Satz aussprechen, dass es höchst sonderbar sei, wie momentan wirkende Traumen ohne jede Einwirkung auf das Linsensystem bleiben, während auch nur kleine Verletzungen in Folge von Operationen so bedeutenden Einfluss ausübten. Sie übersehen dabei, dass Discisionen bei Cataract der tiefer liegenden Linsenschichten meist ohne jeden Erfolg bleiben, dass auch sehr rücksichtslose und gewaltsame Iridictomien ohne Einfluss auf das Linsensystem verlaufen. Da ich bei meinen Verwundungen der Linse ohne jede Schonung verfahren bin, so müsste nach meiner Ansicht jener Satz so geändert werden: bei intactem Linsensystem haben selbst bedeutende Verwundungen der Linse keine Cataractbildung zur Folge; wenn aber ein pathologisch veränderter Theil der Linse verwundet und der Einwirkung des humor aqueus ausgesetzt wird, und wenn überhaupt Bedingungen vorliegen, welche schon zu Cataract geführt haben, so sind sehr bedeutende Folgen zu erwarten.

\section{Ueber die Entstehung und die Folgen der Panophthalmie.}

Die folgenden Untersuchungen waren beinahe vollendet, als ich die erwähnte Arbeit von C. $\mathrm{O}$. Weber und das letzte Heft des Archivs für Ophthalmologie mit der Arbeit von Schweigger zu Gesicht bekam. Dadurch veranlasst, habe ich meine Untersuchungen wiederholt, konnte aber nicht zu anderen Resultaten gelangen. 


\section{Fall.}

Schwarz geflecktes junges Kaninclien mit brauner Iris.

1. Tag. Reclination der Linse in den unteren Theil des Glaskörpers durch einen Einstich $3^{\prime \prime}$ vom Cornearande entfernt. 2. Tag. Die Linse hat sich wieder etwas gehobell, man bemerkt hinter der weiten Pupille nur einen weissen Strich in der Linse, abermals mit der Nadel die Linse gefasst und einige Bewegungen gemacht. 3. Tag. Die Linse liegt nach unten und aussen im Augenhintergrunde und zeigt eine nuregelmässige streifige Trübung, im inneren Quadrarıten eine diffuse Trübung; das übrige Auge blieb völlig ungeindert, keine Gefässbildung, Iris reagirt auf jeden Reiz rasch. Mit der Discisionsnadel wurde num durch die Cornea ein $5^{\prime \prime \prime}$ tiefer Stich bis in die Linse gemacht, durch die klaffende Hornhautwunde floss der humor aqueus längere Zeit ab. Am 4. Tage erschienen schon weisse Flecke nach unten und aussen in der Pupille. Am 5. Tage entwickelten sich nach aussen Conjunctivalgefässe bis zur Cornea, die Pupille war mässig eng, sie war völlig von 2 Trübungen geschlossen, von denen die eine weiss war und mattglänzend, und die inneren 2 Dritttheile der Pupille einnahm, die andere, weisslich gelb, lag vor jener und ging nach vorn iber den Irisrand hinüber in die vordere Kammer. Beginn der Eiterbildung vor der getrübten Linse. Am 7. Tage uiberschritten die Conjunctivalgefässe den Cornearand schon um $1^{\prime \prime}$ im ganzen Umkreise in feinen radiären dicht gestellten $\mathrm{Z}$ weigen. Die Cornea ist leicht rauchig getrübt. Pupille sehr eng, Iris nicht entfärbt, die diffuse weissgelbliche Trübung verdeckt die Linse völlig und nimmt nach aussen einen grossen Theil der vorderen Kammer ein. Am 8., 9. nnd 10, Tage nahm die Gefässbildung und Trïbung der Cornea so zu, dass die Gefässe überall $3^{\prime \prime \prime}$ über den Rand derselben fortgingen. Die Pupille erweiterte sich am 8. etwas; die Iris war am 10. bis auf einen kleinen Theil nach oben vollständig von den gelben Massen in der vorderen Kammer verdeckt, welche sich überall an die Cornea anleg- 
ten und der Schwere nach zu senken schienen; die Cornea war dadurch ganz weiss geworden; ein flüssiges, sich bewegendes Hypopyon war entschieden nicht vorhanden. Meine Diagnose am 10. war danach: Zerfall der Linse vor und hinter der Iris und eitrige Entzündung im Innern des Auges. - Der exstirpirte Bulbus fühlte sich nicht prall an, nach dem Aequatorialschnitt ergoss sich eine trübe, nicht fadenziehende Flüssigkeit. Am Boden der Glaskörperhöhle lag ein linsengrosser, weissgelblicher dicker Klumpen; in der ausgeflossenen Flüssigkeit hatten unregelmässige Fetzen gehangen, welche nun übereinander lagen. Sie giugen von einer weissgelben Masse aus, welche auf der hinteren Wand der Iris und den processus ciliares, sie völlig verdekkend, lag. Diese Masse schickte von ihrer hinteren Seite unregelmässige, theils kürzere, theils längere Fortsätze aus; die kürzeren hatten dieselbe Farbe, und ebenso die längeren an ihrem Ansatze; bei diesen aber wurde die Farbe dann heller, selbst durchscheinend, und sie endigten in jenen flottirenden Fetzen, welche ziemlich durchsichtig waren. Die Masse, welche auf der Iris lag, war nun schwer von ihr zu trennen, um so mehr, da sie bei jedem Zuge riss. Die Pupille war punktförmig. Die Cornea war aufgequollen und von ihrer hinteren Seite mit einer $1 / 2$ " dicken eitergelben Schwarte belegt, welche in der Mitte fest adhärirte, gegen die Peripherie aber lockerer wurde und in unregelmässigen Flocken endigte. Die Iris lag an ilırer vorderen Wand frei da, von wässeriger Flissigkeit fand sich nur sehr wenig. Die Retina lag glatt der Chorioidea an, und löste sich auch von dieser leicht. Die mikroskopische Uutersuchung ergab nun: Die Cornea war trübe, in der Mitte war die Intercellularsubstanz klar, gegen die Descemetsche Membran hin wurden die Kerne der Hornhautkörperchen grösser. Im Bereiche der Gefässneubildung war das Gewebe sehr morsch und zerreisslich; die Intercellularsubstanz war hier streifig und zerfasert, die Kerne der Zellen getheilt, so dass ich einmal drei hintereinander liegen sah, die Entstehung der Gefässe konnte ich nicht nachweisen. Die Descemetsche Membran war überall glatt 
und unverindert, ihre Dicke nahm wie im Normalen, gegen die Ränder der vorderen Kammer allnälig ab. Die Mitte der Schwarte, welche ihr anlag, bestand aus einem engen Faserfilz, welcher nur wenig runde Eiterkörperchen in sich schloss; gegen die Peripherie nahmen die Eiterkörperchen immer mehr zu, die Fasermasse ab und die äussersten Flocken wurden nur von Fiterkörperchen gebildet; in Essigsäure wurde der F'aserfilz durchsichtig und blieb nur leicht gestreift, die Eiterkörperchen zeigten dentliche Kerne. - Die Iris war von weiten Gefüssen durchzogen; die grossen sterufürmigen Pigmentzellen an der vorderen Seite waren völlig ungeändert, die Kerne des eigentlichen stromes offenbar vermehrt; neben den länglichen fanden sich runde; das Gewebe um den Gefüssen war nicht verändert. Die Zellen des Pigmentepithels waren völlig ungeändert. Hinter diesen und den processus ciliares fanden sich grosse Fetzen der völlig glashellen, unveränderten Iinsenkapsel.

Die aus der Glaskörperlühle ausgeflossene Flïssigkeit bestand ans hyalinen, glänzenden, verschieden grossen Kugeln, welche iffers doppelte Contour zeigten, aus lïnglich ruuden Körnchenzellen und Fiterkörperchen, welche einen grossen Kern und meist noch cinige scharf begrenzte runde Kürner enthiclten; laneben fanden sich zuweilen kleine, rauh abgestossen? Reste von Linsenfasern, welche, normal durchsichtion, mit glatten Conturen versehen warell. Jene glänzenden Kugeln und die Körnerzellen hielt ich damals fitr Reste des Glaskürpcrs. -... Der weissgelbe Klımpen am Boden der Glaskürperhöhle wurde zum grössten Theil ans dicht an einander gedrängten kiterkörperchen zusammengesetzt, neben ihmen lag an einzelnen Stellen ein engverfilztes Netz von Fasergewebe, in dessen Maschen wieder Literkörperchen lagen; in Essigsäıre wurde dieser Faserstoff klar und durchsichtig. Die Eiterkörperchen waren gross; im Wasser blahte sich die zarte Hülle sehr rasch auf, der dunkle Inhalt blieb aber cohärent. Sie enthielten fast immer nur einen grossen Kern und mehrere grosse, runde, glimzende Partikelchen, in Fssigsäure unlöslich. .-. Die flottirenden Fetzen 
bestanden aus Stiicken von verbundenen Linsenfasern, welche sich uurregelmässig durchkreuzten; die Conturen der Fasern waren glatt, aber nicht sehr scharf, an den Grenzen der Stiicke waren cinzelne Fasern halb gelöst, andere ganz losgetrennt; diese waren in allen möglichen Richtungen gekräuselt und gewunden, an ihnen lingen zahlreiche Eiterkörperchen und grössere Fetzen von der gefalteten linsenkapsel, öfters auch jene glänzenden kíugeIn und Körnchenzellen. In den trüben Fortsätzen mohrten sich dio Eiterzellen den Jinsenfasern gegeniiber; die IIauptmasse selbst wurde aus einzelnen kurzen, abgesplitterten Linsenfasern und dicht gedrängten Witerkörperchen zusammengesetzt.

An der Retina lomnte ich damals nichts Abuormes erkemnen, alle Schichten waren deutlich erkembar. Stïbchen, Körner, grautulöse Schicht, Nervenzellen und Fasern, sowie die Radialfasern waren scheinbar ohne jede Veränderung.

Die Farbe der Choroidea war etwas zu hell und es bildete sich bei längerem Liegen in chromsaurem Kali ein weissgelblicher Beschlag anf ihr, welcher aus runden kleinen Eiterzellen bestand ohne Kerue. Das feinere Epithel iiber den processus ciliares war normal, dagegen war das der Chorioidea selbst verändert; die Zellen platzten bei jedem Druck anf das leichteste; sie hatten durchaus nicht dieselbe Grïsse, sondern manche waren drei- und vierfach so gross, als die lieineren; ibre Form war rund und mit abgestumpften Ecken, viele hatten Ausbuchtungen. Das Pigment bildete einen schmalen Saum um den Rand der Zellen und liess einen ziemlich grossen Raum in der Mitte frei, in wclchem ein oder zwei Kerne lagen; durch diesen Raum konnte man die Kerne der eigentlichen Chorioidea deutlich unterscheiden. - Die Kerne der Stromazellen in der Chorioidea waren gross und neben ihnen fanden sich noch runde Zellen ohne Kern und Kernkörperchen, dereu Natur ich nicht zu bestimmen vermochte. Die ästigen Pigmentzellen des Stromas waren völlig ungeändert; eine besondere Gefässvermehrung liess sich durchaus nicht nachweisen. - Es lag hier also ein Fall von diffuser Eiterbildung im Innem des 
Auges vor mit Zersprengung der Linse; den Thatbestand hatte ich möglichst festgestellt, obne irgend einen Zusammenhang desselben zu crkemen.

\section{Fiall.}

Mittelgrosses, junges, schwarz und woiss geflecktes Kaninchen.

Am 1. Tage wurde mit der Reclinationsnadel durch die Sclerotica die Jinse gefasst und stark gegen den Chorioideagrund gequetscht; unmittelbar nachher gab die Iinse am Boden des Glaskörpers cinen trüiben Schein. Am 3. 'Iage waren trïbe staarflocken nach unten und aussen zu erkennen. $\Lambda$ m 4. Tage war der Augenhintergrund durch einen weissen Schleier verdeckt, welcher der Retina dicht inflagr; nach aussen lagen dickere getribte Massen. Dic P'upille weit und eine Fintwickelung von Conjunctivalgefässen fand nicht statt. Ich ging daher noch eimmal mit der Reclinationsnadel ein, um grösserc Reste zı zcrtlıcilen, konnte aber nichts aufspiessen. Am 5. war dic Conjunctiva sowohl der Augenlider, als des Bulbus mässirg chemotisch, überall mit feinen Gefässen injicirt, deren Menge sich rings um den schwarzen Rand der Ilornlıat sichtlich anläuft, diesen aber nirgends ïbersehreitet. Die Cornea erscheint rauchig getriibt, wahrschininlich durch cinen ihrer hinteren Fläche atifliegenden gelblichen Beschlag. Der untere Theil der vorderen Augenkammer bis zur Mitte der Pupille, die P'upille ganz und im geringen Maasse dic obere Hälfte der Kammer sind mit einer triib-gelblichen Masse gefüllt, welche in Hockigen Schichton liegt. Nach dem früberen Befunde musste ich sie für nicht flussigen Eiter halten. Die Iris schimmerte nur im oberen Quadranten etwas durch diese Masse hindurch. Am 6. Tage hatte die Gefässinjection der Conjunctiva noch zugenommen, die Cornea war völlig frei von Gefüssen, hatte aber durch die ihr inliegenden Massen ein ganz weisses Ansehen bekommen, ohne dass sie selbst getrübt wäre. Die Kitermassen in der vorderen Kammer halen sich gesenkt, erfillen nun den ganzen unteren Theil bis zum oberen Rande der Pupille. lassen aber den oheren Quadranten der Iris dent- 
lich sehen, er scheint etwas verfurbt. Die Kitermasse ist aber durchaus nicht beweglich. Am 12. Tage fand sich die Cornea ungetrübt, im unteren Drittel der Conjunctiva hatten sich sehr starke Gefässe entwickelt und von ihnen gingen feine radiäre Gefässe auf die Hornhant uber und iiberschritten den Rand in der Mitte etwa $3^{\prime \prime}$. Die Pupille war mässig weit und mit einem weissen Pfropf gefüllt, welcher sich in die vordere Kammer drängte und nach unten der Cornea anlag. Die Iris war roth gefärbt, das Kammerwasser nicht getrübt. Die Eitermassen in der vorderen Kammer waren daher sehr zusammengeschrumpft. - Im Ganzen erwartete ich denselben Zustand, wie im 1. Fall, nur etwas weiter vorgeschritten.

Nach der Exstirpation floss beim Aequatorialschnitt eine trübe Flüssigkeit aus, welche die kleinere Hälfte des hinteren Augabschnittes erfüllte; die vordere Hälfte war von einer weissen, dicht gefalteten, leicht zerreisslichen Masse gefüllt, welche von den processus ciliares und der uvea leicht zu trennen war und nur am $\mathrm{Pu}$ pillarrande der Iris fest anhing. Diese Masse im hinteren Angenabschnitte setzte sich unmittelbar in den gelben Pfropf fort, welcher am Boden der vorderen Kammer lag. Dieser war selur zähe und fest, hing übrigens keiner der begrenzenden Häute, weder der Iris noch der Cornea fest an. Die Retina war von der Chorioidea getrennt und lag ihr nur ganz lose an. Die triibe, ausgeflossene Flïssigkeit bestand aus Eiterkörperchen und Körnchenzellen, welche in einer durchsichtigen Flüssigkeit suspendirt waren; diese coagulirte in Essigsäure, ohne weitere Bildungen zu zeigen. Die Eiterkörperehen waren sehr gross, alle von gleicher Grösse, sie bestanden aus einer äusserst feinen Membran, welche sich in Wasser abhob und bei Essigsäurezusatz bald verschwand, und einem dunklen cohärirenden Inbalt, welcher sich gegen Essigsäure ziemlich indifferent verhielt und nur selten mit Bestimmtheit einen Kern erkennen liess. - Die weisse, gefaltete Masse bestand aus Eiterkörperchen und Linsenresten. Die Linsenfasern hingen meist nicht mehr zusammen, die einzelne Faser war nicht gerade, sondern in allen mög- 
lichen Richtungen gewunden, der Glanz war verloren, sie sahen dunkel aus und waren mit feinen Körnchen besetzt, und ihre Conturen waren ganz unregelmässig grob und fein gezackt. In Essigsäure verschwanden die feinen Pünktchen, dic Fasern wurden wieder glänzend, durchsichtig, erhielten parallele Conturen, welche nur noch hier und da gezackt blieben. Es war hier offenbar eine Metamorphose des Faserinhalts vor sich gegangen, durch welche die Faser ihren durchscheinenden Glanz und die pralle Glätte der Contur verloren hatte. Die Eiterkörperchen verloren von der Oberfläche nach der Mitte der weissen Masse immer mehr ihren dunklen resistenten Inhalt, dic Hülle dagegen wurde gegen Wasser und selbst Essigsäure resistenter und in dem klar werdenden Inhalt traten kleine Kerne auf, erst einzeln, danu zu zweien und endlich zu mehreren, so dass oftenbar hierin eine fortschreitende Metamorphose der Eiterkörperchen von der Oberflüehe gegen die Mitte jener Masse zu erkennen war. Der weisse Pfropf in der vorderen Augenkammer war sehr zähe und schwer zerreisslich und liess sich ziemlich glatt schneiden, an der Oberfläche bestand er nur aus dicht gedrängten Eiterkörperchen mit klarem Inhalt und deutlichen, vielzähligen Kernen. Die Iülle war derb, in der Mitte dagegen trat eine fasrige $Z$ wischensubstanz auf, welche den grössten Theil bildete; in ihren Maschen lagen Eiterkörperchen, ihre Faserung trat besonders nach Essigsäurezusatz horvor und war unregelmässig punktirt. Hicr trat also Faserstof' neben den Eiterkörperchen auf. - Die Retina war etwas mürbe, wie macerirt, dic erste oberflächliche Untersuchung liess nichts abnormes erkennen; die Stäbchen waren normal, die Körner $1 / 3 \ldots 1 / 2$ so gross als die Eiterkörperchen, hingen au den Radialfasern, waren aber sehr glänzend. Die Radialfasern waren glatt; die Zellen leicht punktirt; die Continuitätstrennungen waren nirgends zu bemerker. Nur bei wiederholtem Nachsuchen war es mir auffallend, dass die Aeste der Nervenfasern so weit verfolgt werden konnten und ihr husammenhang mit den Radialfasern so hänfig zu sehen war; dann bemerkte ich allch eine länglich ruude Form von Ker- 
nen in den Radialfaserı, welche hauptsächlich zwischen innerer Körnerschicht und granulöser Schicht angelä̈uft lagen und dieser Gegend ein der Nervenzellenshicht äbnliches Ansehen gaben.

Zwischen Retina und Chorioidea hingen kleine, dünne, gclbe Schollen; sie bestanden zum grössten Theil aus kleinen runden Zellen, welche $\frac{1}{3}-\frac{1}{2}-\frac{2}{3}$ so gross, als die Eiterkörperchen im Glaskörper waren, aus einer resistenten, in Essigsäure sich nicht auflösendeu Hülle und einem dunklen, undurelsichtigen Inhalt bestanden, ein Kern war in ihnen nicht zu erkennen. Auf Essigsäurezusatz trat zwischen diesen Zellen eine geringe Menge von Faserstoff hervor, faserig, fein punktirt, nur schr selten, vielleicht zufällig, fanden sich ausgebildete Eiterkörperchen.

Die Zellen des Chorioidealepithels hatten eine sehr verschiedene Grösse und Form, waren sonst aber völlig normal: glashelle Zellen, die Randtheile dicht mit Pigmentkörnern gefüllt und in der durchsichtigen Mitte einen Kern enthaltend; öfters als gewöhnlich schienen sie mir allerdings zwei Kerne zu enthalten. Ebenso waren die ästigen Pigmentzellen des eigentlichen Chorioideastromes völlig ungeändert, bis auf den mittleren Kern strotzend von Pigment gefüllt, anostomosirten sie mit breiten und schmalen Aesten auf das mamichfachste mit einander. Dagegen waren die eigentlichen Stromazellen entschieden verändert. Sie bilden die Grundlage der Chorioidea, in ihnen eingebettet liegen die Gefässe, welche von dichteren Bindegewebsstreifen und einzelnen Muskelfasern umgeben werden. Die Form der Zellen war normal spindelförmig, die Farbe glashell und durchsichtig. Dagegen wurden sie sehr verdickt durch ihren Inhalt, die Kerne; diese waren sehr gross, bis doppelt so gross, als normal, sie erfiullten die Breite der SpindeIzelle vollkommen und trieben sie seitlich oft so auf, dass der Charakter der Spindelzelle verloren ging, sie enthielten bei genauer Einstellung alle ein Kernkörperchen und waren von einem gelblichen Inhalt prall erfillt, welcher in den vom Kern ausgebuchiteten Zellen sich zuweilen so differencirte, dass man in der einen Spitze, die Hïlfte des Kerns einnehmend, die schwache 
Contontr cines runden hö̈lpers unterscheiden konnte. Bei einigen Kernen zeigten sich seichte Linschnurungen in der Hembran, wie zur 'Theilung der Zelle. Dann lagen aber in dem stroma noch andere Gebilde, rund, grainzend, hellgelb, sie lagen in den Maschen des Gewebes, bestanden aus einer grgen Wasser und Eissigsäuro resistenten lliille und einem yelben Inhalt, enthielten keinen keru und waren $1 / 3 \ldots 1 / 2$ so gross, als die Stromakerne, kurz sie glichen, bis auf den sehr' geringen Grössenunterschied wanz genall den der ('/u) rioidea anhängenden Zellen. Sirs lagen sehr dicht bui cinanter, aber doch nie in Haufen, sondern ganz unregelmässig und cinzeln; wie gesagt, konnte ich ilır Lintstchen aus den Stromazellen nicht bestinimt nachweisen, da ich nie einen getheilten Kern und diese Körper immer ausserhalb der Zellen sah, doch musste ein solcher Znsammenhang nach der angedenteten 'Theilung der Kerne sicher statuirt werden. Die Zahl dieser Körper und die Vergrösscrmng der home malım nach der Sclera lin immer mehr ab. Mit den Gefässen schienen diese Vorgainge nicht in Zusammenhang zu stehen, da das diese begleitende lindegewebe und die Kerne der Muskelzellen durchaus kcine Veränderung erkennen liessen. -- Duch waren dic Gefüsse sehr weit.

Die Iris entsprach ganz genan den Verïnderungen der Chorioidea, die I'igmentzellen der Uvea und die astigen l'igmentzcllen an der vorderen seite der Iris waren normal, die (iefaisse weit und ilne Bindegewebsstränge ohne Veräunderung, neben den Muskelfaserkernen und den Kernen ler Stromazellen, welche stark vergrössert waren, finden sich noch sehr zahlreich jene runden Körper, welehe ieh nicht fïr Kerne und nicht fiir Zellen ansprechen konnte.

In unteren Theile der Cornea, in welchem sich die radiären Gefässe verzweigten, enthielten die Hornhautkörperchen grosse Kerne, einzelne hatten sich getheilt, es lagen in ten Zellen zwei, auch wohl drei lierne zusammen. Ein Zusammenhang mit der Gefässbildung watr nicht zu entdecken. - Ich war durch diese Lutersuchung allerdings der (ienese des Eiters im Innern des Auges um einige Schritte näher geriuckt, indem ich 
nun die Chorioidea als Ort derselben bezeichnen konnte und zwar noch genauer die Stromazellen derselben, allein bis zur völligen Sicherheit fehlten doch noch viele $Z$ wischenglieder und besonders der Marsch derselben in den Glaskörper. Jedenfalls schien mir aber soviel fest zu stehen, dass die Entwicklung des Eiters in zwei Perioden zu scheiden sei: 1) Bildung der Körperchen in der Chorioidea, 2) Entwicklung derselben nach ihrem Austritt aus dieser Membran.

\section{Fall.}

Altes buntes Kaninchen. Das Auge war schon zur Dilaceration der vorderen Kapsel benutzt und später der Linsenvorfall durch lineare Extraction entfernt. Am 3. Tage nachher fand sich ein weit grösserer getrubter Linsenvorfall, welcher in der wenig gefüllten vorderen Kammer bis zur Cornea reichte und überall mit dem Irisrande zusammenhing. Am 6. 'Tage war die Anlagerung der Iris an den Vorfall nicht mehr durch Atropin zu tremnen. Es wurde dann die Reclination von der Sclera aus gemacht und durch die vorgeschriebene Bewegung die Linse nach hinten und unten dislocirt. Die Pupille und die getrübte Masse in ihr blieben dabei ohne jede Bewegung an ihrer Stelle. Am 8. Tage lagen in der Cornea nach oben und nach anssen $z$ wei flache weisse Infiltrationen parallel dem schwarzen Cornearande, welcher ihnen entsprechend etwas verwaschen ist und von feinen Gefässen durchbrochen wird. Die Conjunctiva ist rings un die Cornea stark ödematös, infiltrirt und von Gefässen durchsetzt. Die vordere Kammer blieb sehr flach, an manchen Stellen schienen Iris und Cornea mit einander verklebt zu sein. Die Farbe der Iris ist im oberen Quadranten heller geworden und am äusseren Rande sind dicke Gefässe, nach innen feinere zu sehen. Am 15. Tage war an der Stelle der Corneainfiltrationen nur noch eine blassweisse Färbung der Cornea zul bemerken; die Corneagefässe hatten sich zurtickgebildet, dagegen die Gefässe der Conjunctiva sehr vermehrt. Iie tribe Linsenmasse in der Mitte der vorderen Kammer schien geschwunden, an ihrer Stelle zog sich von der Mitte 
der Iris zur Cornea ein feiner, pigmentirter Streifen. Die Pupilleuränder waren vollständig untereinander verwachsen. Die Entfärbung der Iris war dieselbe. Am 25. Tage bestand noch immer eine leichte Chemose der Conjunctiva; die Gefässe des ganzen Conjunctivalsackes sind äusserst entwickelt, sie überschreiten im ganzen Umkreise mit Ausnahme eines kleinen Stückes nach innen und oben, den ganz verwasehenen Cornearand. Diese Corneagefässe liegen oberflächlich, laufen radiär gegen den Mittelpunkt, theilen sich dabei dichotomisch und haben eine Lïnge von $2-2^{1} / 2^{\prime \prime}$. Zwischen ihnen ist die Cornea gleichmässig leicht getrübt. Die Iris ist röthlich entfärbt, die vordere Kammer schr flach; die Pupille ist wieder etwas geöflnet und von einer weisslichen unregelmässigen Masse erfïllt, welche sich gegen den Boden der vorderen Kammer in einem gelben Pfropf fortsetzt. Dieser Pfropf weicht bei Druck auf das Auge hin und her. Die Sclera war hinter der Corneainsertion sehr stark gewülbt und das Ange eher etwas härter anzufüllen. Ich vermuthete eine bedentende Eiterbildung im hinteren Augenabschnitte, welche zuletzt selbst die Verwachsung der Pupille getrennt und festen Eiter in die vordere Kammer ergossen hatte. Bei der $\mathbf{E}_{\mathbf{X}}$ stirpation bluteten die Gefässe sehr stark.

Sectionsbefund. Die Gefässe der Hornhant lagen alle dicht unter dem Epithel der vorderen Wand, sie hatten ein bedeutendes Lumen und ziemlich dicke Wandungen, zum Theil mit quergelagerten Kernen. Die Hornhautkörperchen zeigten durch die ganze Cornea genau dieselbe Beschaffenheit, sie batten grosse, theils runde, theils längliche Kerne, aber nie mehr als einen; ein Zusammenhang derselben mit der Gefässbildung musste daher unmöglich erscheinen, diese konnte nur von den Conjunctivagefässen ausgegangen sein. Die Descemet'sche Membran war völlig normal, aber an vielen einzelnen Stellen mit der Oberfläche der Iris verklebt, und zwar geschah dies durch kleine gelbe Haufen, welche nur von Eiterkörperchen zusammengesetzt wurden. Alle Flüssigkeiten des Auges reagirten dentlich alkalisch. Aus der vorderen Kammer floss nur eine geringe Menge humor aqueus aus, der Pflock 
in derselben hängt mit der gelben Masse in der Pupille zusammen, doch haftet diese uiberall am Pupillarrande fest und setzt sich nicht weiter nach hinten fort. Beide bestehen aus eng gedräıgten Eiterkörperchen und einer netzförmigen, leicht faserig gestreiften Masse, welche in Essigsäure durchsichtig wird. Die Farbe der Iris ist ein durchscheinendes Braun durch einen feinen gelben Beleg, welcher an manchen Stellen stärker hervortritt und besonders um den inneren Pupillarrand einen stirkeren Ring bildet. Diese dünne, der Iris aufliegende Schicht kann von ihr durchaus nicht abgezogen werden, sie besteht nur aus Eiterkörperchen. Das Gewebe der Iris ist aufgequollen; zahlreiche, weite Gefässe durchlaufen es; das hintere Uveacpithel zeigt wohl erhaltene Zellen bis auf den Pupillenrand, an dem einige Zellen zerstört und nur noch Pigmenthaufen zurückgelassen zu haben scheinen; das eigentliche Stroma ist von unzähligen Kernen und runden Zellen durchsetzt; die letzteren liegen scheinbar frei in dem Gewebe, sie sind wenig kleiner, als Eiterkörperchen, sind von einem trüben Inhalt erfïllt, ohne dentlichen Kern; die Kerne des Stroma's sind oval, gross bis zur doppelten Grösse jener Zellen, enthalten deutlich ein bis zwei Kernkörperchen und zeigen vielfach Einschnürungen in der Mitte; seltener sieht man Kerne, in denen sich der Inhalt um zwei Kernkörpcrchen getheilt hat und die Membran noch nicht so weit in der Abschnürung gelangt ist. Es gelıen so aus den Kernen zwei Gebilde hervor, welche jenen runden Zellen identisch sind und müssen die Eiterkörperchen, welche aus der Iris entstehen, für getheilte Zellenkerne angesehen werden. Besonders betheiligen sich an diesem Process die Kerne der Stromazellen und Muskelfasern, während die Zellen des Bindegewebes nur durch Vermehrung des Inhaltes rund geworden sind. Die vorderen Pigmentzellen waren unverändert, nur in der Nähe des Pupillenrandes und in der Zellenmasse der Iris lagen einzelne Pigmentklumpen vor, an denen die Aeste fehltell. In der Nitte der Pupille lag eine durchsichtige scholle ohne Structur, welche nach Essigsäurezusatz aus Linsenfasern bestand. 
Der ganze hintere Augabschnitt war von einer gelben schmierigen Masse erfüllt, von dem Glaskörper fand sich nirgends ein Rest, aber in dem vorderen Theil der Masse lag der grösste Theil der Linse. Diese war' ziemlich durchsichtig, aber doch gleichmässig getrübt, ihre Ränder uneben; nur ein kleiner losgetrennter Theil des Linse ruhte auf den unteren processus ciliares. Dem mikroscopischen Verhalten nach erschien die Mitte des Linsenkeriis normal bis auf einige leichte Abweichungen in der Breite der $/ /$ wischenräume $z$ wischen den einzelnen Fascrn. An der Aussenfläche der grossen Masse hingen den Fasern iiberall Witerkörperchen an, die Fasern selbst waren an cinem Ende losgetrennt, hatten ihre Durchsichtigkeit bewahrt, ihre Membran war nach aller Seiten unregelmässig ausgezackt (Fig. $3 \mathrm{~b}$ und c); neben ihnen lagen cinzelne runde Kugeln bis zur dreifachen Grösse der Eiterkörperchen, welche sebr stark glänzten und öfters eine und selbst zwei kleinere Kugeln enthielten. (Fig. 3 a). Sie sind wohl als Faserinhalt aufzufussen und jedenfalls sehon während des Lebens entstanden. Sic traten bei $\bar{A} e$ noch mehr hervor, verloren bei lüngerer Finwirkung der Säure ihren Glanz und wurden leicht punktirt, am spätesten die inneren Kugeh. An dem kleineren Linsenstïck gingen die Veräinderungen der Röhren noch weiter, sie waren zum grössten 'Theil losgerissen, hin und her geschwungen, wurden bald schmal, bald breit, öfters zeigten sie feine Punktirmo. Neben den Fasern lagen grosse Mengen jener Kugeln. In den umgebenden Eitermassen lagen damn noch in buntem Gewirre ebenso veränderte Faserı, sie fanden sich noch weit gegen den Hintergrund lin. Auf den processus ciliares lagen völlig unversehrte Reste der Kapsel. -

Die Eitermenge erfïllte den Glaskörperraum so vollständig, dass sie einen sehr zierlichen Abdruck der Falten der processus ciliares lieferte; sie lag der Retina dicht an und konnte an vielen Stellen nur mit starkem Zug von ihr getrennt werden, indem Fetzen der Masse an der Retina oder Theile dieser an jener hängen blieben. Die Masse bestand nur aus dicht ancinander gedrängten runden Eiterkörperchen, meist mit 
einem, zuweilen mit zwei und drei Kernen; der Inhalt derselben war dunkel contourirt und fest zusammenhängend, von ihm hob sich durch $\bar{A} c$ eine dünne durchsichtige Membran ab. Fine Zwischensubstanz zwischen den Eiterkörperchen war auf keine Weise sichtbar zu machen. Von einer Mutterzellenbildung im Glaskörper konnte ich trotz langem Suchen nichts entdecken. Durch die ganze Masse zerstreut, meist aber vor der Retina lagen Fetzen einer Glasmembran vou sehr verschiedener Grösse, gradlinigt und ausgerissen, sie hatten keine Dicke, waren aber vielfach und unregelmässig durchlöchert. Zum grössten Theil gehörten sie wohl der hyaloidea an, die durchlöcherten Fetzen möchte ich dagegen zur limitans rechnen.

Die Retina war in hohem Grade verändert; überall lagen in ihr Eiterkörperchen zerstreut; die Elemente der Netzhaut waren ungewöhnlich leicht zu isoliren, so dass offenbar die Cohärenz derselben verloren gegangelı war. Die Stäbchen waren zum grossen Theile untergegangen, denn uur sehr selten fanden sie sich erhalten, diese bestanden aus einer feinen Hülle und krümlichem Inhalt. Die Körner der äusseren Körnerschicht waren ausserordentlich glänzend nnd schienen vergrössert. Die Radialfasern hatten ihre Glätte und Glanz verloren, sie waren blass und viel breiter, als normal, hier und da lagen in ihrem Verlaufe einzelne glänzende Punkte, welche an Stellen, entsprechend den inneren Körnern, kleine Haufen bildeten. Dann fanden sich aber noch in den meisten Fasern grosse längliche Kerne mit Kernkörpe:chen, sie übertrafen die normalen Körneranschwellungen beträchtlich und einer fand sich in Theilung begriffen; in ihrer Nähe lagen immer mehrere solcher glänzenden Körper. Aehnlich waren die Nervenzellen verändert; ihr Zusammenhang unter einander, mit den Nervenfasern und mit den Radialfasern liess sich sehr häufig erkennen, die Zellenfortsätze waren immer sehr zahlreich und lang. Der Inhalt der Zellen war nicht fein granulirt, sondern in jene glänzende Moleciile zerfallelı, welche der Essigsäure widerstanden; die Kerne sehr gross, oft die halbe Zelle erfüllend. In manchen Zellen fanden sich zwei, in einer selbst drei 
Kerne und man konnte die Theilungsvorgänge deutlich verfolgen, erst zwei Kernkörperchen in einem Kerne, dann Abschniirung der Membran und zuletzt zwei Kerne nebeneinander. Die Nervenfasern zeigten keine Besonderheiten, aber von der limitans und den Insertionen der Radialfasern in diese war in Zusammenhang mit der Retina nichts zu entdecken. Soviel ich an Querschnitten sehen konnte, lagen die Kerme in den Radialfasern alle in einer Schicht zwischen innerer Körnerschicht und granulöser Schicht. - Das Gewebe der zonula Zinnii war durchsichtig und ungeändert.

Chorioidea und Retina hingen iberall sehr fest zusammen und waren nirgends von einander zu trennen. Das Pigmentepithel der Chorioidea zeigte auf den processus eiliares durchaus keine Abweichung, auf der eigentlichen Chorioidea waren die Zellen sehr verschieden gross, lagen ohne die schöne Ordnung aneinander, das Pigment in ihnen war ganz unregelmässig zerstrent. Das Stroma der Chorioidea war nicht gleichmässig, an manchen Stellen schien es nur aus runden Zellen zusammengesetzt $z 11$ sein, welche etwas kleiner als Eiterkörpcrchen waren, an anderen Stellen trat der faserige Bau mehr hervor, die Kerne der Stromazellen waren weit grösser und zeigten durch zahlreiche, bei der Iris schon erwähnte 'Theilungsvorgänge den Ueber' gang in jene runden Zellen, wenn es danach iiberhaupt erlaubt ist, sic als Zellen zu bezeichnen. Eben dieselben Veränderungen hatten in den Kernen des tensor chorioideae begonnen. Die ästigen Pigmentzellen der äusseren Chorioideaschichten waren zum grössten Theil unversehrt, nur an einzelnen Zellen war der Zusam. menhang zwischen den Aesten und der eigentlichen Zelle zerstört, und es fanden sich dann nur freie Pigmenthaufen ohne Kern. Die Gefässe der Chorioidea waren sehr zahlreich and weit.

Die Beschaffenheit der Retina gab in diesem Falle sehr schöne Auskunft über die Wanderung der in der Chorioidea gebildeten Eiterkörperehen in den Glaskörper. Die Veränderungen der Radialfasern und der Nervenzellen komiten wohl nicht anders aufgefasst 
werden, als fettiger Zerfall des Inhaltes und Zunahme und Theilung der Kerne.

\section{Fall.}

Junges geflecktes Kaninchen. In dem Auge (Fall $5 \mathrm{der}$ Discision) war durch drei einfache, aber tief gehende Discisionen Eiterbildung im hinteren Augenabschnitt hervorgerufen. Das Auge war sehr weich. Exstirpation am 16. 'Tage nach der ersten Verwundung.

Sectionsbefund. Dic Contenta erfüllten deil Bulbus nicht melır völlig. Eine gelbe schmierige Masse lag in dem hinteren Augenabschnitt, vom Glaskörper war keine Spur zu finden. Durch vorsichtiges Präpariren liess sich die Masse an einzelnen Stellen vollständig von der Retina abtrennen, an anderen dagegen folgte dem Zuge derselben Retina und Chorioidea, ihr fest anhangend; so dass nur die sogenannte lamina fusca der Sclera anhaftete. Die Masse reichte bis zur Pupille und schloss in ihrem vorderen Theile die zusammenhängende Linse ein.

Die Fasern der Linse hingen meistens in grösseren Schollen zusammen, ohne dass einzelne am Raude abgesprengt waren; die Breite der einzelnen Fasern hatte ahgenommen, sie standen, durch dunkle $Z$ wischenräume getrennt, ziemlich weit von einander ab; die Contouren waren nicht glatt, häufig unterbrochen und zackig, der Inhalt zum Theil in kleine Partikel zerfallen; in Essigsäure wurden die Fasern aufgehellt, die kleinen Molecule bis auf einige kleine dunkle Pünktchen gelöst, doch wurde die Membran nicht wieder glatt und der Glanz der Fasern kehrte nicht zurück. - Die gelbe Masse war leicht zerreisslich, aber doch ziemlich cohärent, sie bestand aus Eiterkörperchen und einer netzförmig angeordneten Intcrcellularsubstanz, welche in Essigsäure ganz durchsichtig wurde und eine feine Punktirung zeigte. Die Membranen der Eiterkörperchen blähten sich nur bei wenigen auf, die meisten enthielten einen oder mehrere kleine Kerne und neben diesen noch viele punktförmige dunkle Kernchen, Essigsäure machte den Inhalt der Eiterkörperchen durch- 
sichtig und löste einen Theil jener Körner. Neben diesen Eiterelementen fanden sich, aber in der Masse zerstreut, melirere andere Gebildte. Hier und da lagen einzelne grosse Körnchenzellen, doppelt und dreifach so gross, als Witerkörporchen, sie wurden aus ziemlich grossen, dunkelglianzenden Körnchen zusammengesetzt, ein Kern fehlte, doch besassen viele deutlich cine feine Nembran, welche an andern nicht unterscheidbar war. An einen leborgang der Hiterkïrperchen in diese Kellen konnte nicht gedaclit werden, da eine riickgängige Metamorphose derselben nicht vorlag; die früher nachgewies'nen Zellon der Ilyaloidea, welchen sie in Grösse und Form vïllik entsprachen, senuigten anch zu ihrer lirklärungr. Danı sah man schr häıffig wasserhelle Schleimkugeln uberall in der Masse, sie stammten, wie frühere Präparate bewiesen, aus der lietina, nicht selten enthiclten sie noch eine zweite in sich. Endlich lagen ziemlich weit in der Eitermenge Radialfasern und an einer Stelle dicht vor der Retina Nervenzellen zwischen den Eitcrkörperchen. Ile Radialfasern waren so breit (Fig. \& abc.), dass ich anfangs zauderte, sie für solche zu erklären, sie hatten ziemlich scharfe Contouren, endigten natiirlich abyrerissen, enthielten viele feine und grösssere Moleciile und meistens einen länglichen Kern mit grossen Kernkïrperchen. Die Nervenzellen lagen in cincm Neste zusammen, sic hatten so viele Aeste und anastomosirten so breit miteinander. wie man es bei der l'raparation normaler Netzhäute nie zu selien bekommt ( $\mathrm{Fig}$ 5a). Sie enthielten alle einen Kern und viele glänzende Körnchen.

Die Retina selbst war selnr matsch und zerriss in allen Richtungen leicht. Nur an wenigen Stellen lagen alle Schichten übercinander, am meisten waren die inneren Schichten zerstört; der Zusammenhang der einzeInen Elemente war sehr gering; uberall lagen Eiterkörperchen zwischen ihnen. Die erhaltenen stäbchen waren glanzlos und blass, doch die meisten zerstört und in kleine Stücke zerbrochen. Die äusseren Körner enthielten keinen homogenen, sondern grobkrümeligen Inhalt; sie hatten ihre runde Form nicht bewahrt, soudern waren vielfach eckig; zwichen ihnen lagen 
sehr viel solche durchsichtige Schleimkugeln, welche aber vielleicht als Präparationsprodukt anzusehen sind. Die Radialfasel'n waren nicht uiberall gleich; an einigen Stellen nur wenig verändert, scharf conturirt, glänzend, selten in der Mitte fein punktirt, an anderen dagegen liessen sich nur einzelne finden, welche winklig hin und her gebogen und iiberall fein und grob punktirt waren; Essigsäure blieb ohne jeden Einfluss auf diese Punktirung. Dic meisten der Radialfasern enthielten einen länglichen Kern. Die Nervenzellen fehlten ebenfalls an vielen Orten; wo sie zu finden waren, zeigte sich ihr Inhalt grobkörnig, die Kerne vergrössert; einzelne Zellen allerdings zeigten durch fein granulirten Inhalt und kleine Kerne an, dass sie an diesen Veränderungen noch nicht Theil genommen hatten. Die Fasern des Opticus komnte ich nirgends erkenmen, die limitans hing in grossen Fetzen zusammen und es war keine Veränderung an ihr zu bemerken.

Die Chorioidea hing also der Retion schr fest an, trennte sich dagegen leicht von der Sclera. Das Pigmentepithel zeigte bis zur Uvea der Iris hin sehr beträchtliehe Veränderungen; die Zellen hatten eine sehr ungleiche Grösse, manche waren vergrössert, hatten Ausbuchtungen bekommen und pressten kleinere zwischen sich zusammen. Das l'igment war in allen regellos zerstreut, bald leere Stellen, bald dicke Anhäufungen; die Kerne liessen sich in den meisten unverändert erkennen. An einzelnen Stellen war die Zerstörung der Zellen bewirkt, das Pigment lag uberall frei umber. Das Stroma der Chorioidea schien in ziemlicher Ausdehnung nur aus kleinen runden Zellen zusammengesetzt, welche eng gepresst aneinander lagen, und keinen anderen Gewebstheil erkennen liessen; sie waren über halb so gross, als Eiterkörperchen und viele enthielten bei Essigsäure ein rundes Körperchen in sich. Diese Zelienhaufen fanden sich in der Chorioidea zerstreut, an ihren Grenzen trat das fasrige Gefüge wieder hervor und waren einzelne ovale, in Theilung begriffene Kerne der Faserzellen sichtbar. Um sie herum war das Stroma verhältnissmässig normal, die Kerne der Zellen vergrössert und vielfach die Mo- 
mente der Theilung anfklairend, dass ein Uebergang dieser getheilten Kerne in jene runden Zellen nicht zu bezweifeln war. Durch die Chorioidea zogen sich wohl erhaltene, durchsichtige Bindegewebszüge, Nerven oder Gefässe unmittelbar ungebend, sie liessen noch keine Veränderung bemerken. Die Pigmentzellen des Stroma's waren znm grössten Theil wohl erhalten, dagegen schien die Membrun einzelner Aeste Lücken zu haben, da sie, wenn anch das Pigment noch zusammenlag, doch nicht mehr dentlich begrenzt waren. --. Die Iris zeigte nur geringe Spuren ähnlicher Veränderungen, die vordere Kammer war aber anch ganz frei von Fiter.

Der untere Rand der Cornea, in welchem sich die nengebildeten Gefässe befanden, war ziemlich morsch, die Kerne der Hornluantkörperchen stark vergrössert; aber nirgends liessen sich Theilungen derselben and ein Zusammenhang der Hornhautkörperchen mit der Gefässbildung erkennen.

\section{Fall.}

Junges, geflecktes Kaninchen. Nachdem zehm Tage zuvor in der Mitte der Linse eine ansgiebige Discision gemacht war und sich der vorgefallene Linsentheil, welcher keine Verklebung mit der Iris eingegangen war, schou wieder sehr verkleinert hatte, wurde die Reclination versucht und ein dabei gefasstes Linsenstitck gegen die Bulbuswand gequetscht. Schon am dritten Tage entwickelten sich reichliche Conjunctivagefässe, die Pupille war sehr eng und hinter ihr eine gelbe Masse erkennbar. Am sechsten Tage wurde das Auge exstirpirt.

Sectionsbefund. Nach dem Aequatorialschnitt fand sich am Boden der Glaskörperhöhle ein erbsengrosser Eiterklumpen, iiber welchen eine trichterförmig abgelöste Membran, die Hyaloidea, fort ging. Retina und Chorioidea lagen der Bulbuswand fest an. Die Linse hatte ihre Form bewahrt, war aber an der linteren Seite durch einen horizontalen Strich eingekerbt und mit vier kleinen Eiterklımpen bedeckt, deren einer sich an der zonula fortsetzte. - Die hintere Kapsel 
hatte in der Mitte einen langen Riss, aber durchaus keine Veränderung ihres Gewebes erlitten; die Eiter massen lagen ihrer hinteren Seite auf. Die Linse war sehr weich, in ihrer Mitte lagen viele zertrümmerte Linsenfasern, kleine, zerrissene Stücke; die Membranen der Fasern waren noch glatt und ihr Inhalt zeigte nur eine feine Punktirung, so dass der Glanz und die Durchsichtigkeit zum grössten Theil noch bewahrt waren. Bei näherem Durchsuelien der Kernzone bemerkte ich eine Veränderung der Kerne, auf welche ich früher nicht geachtet hatte; der Inhalt derselben hatte sich in grosse dunkle Körner getheilt, Essigsäure blieb ohne Einfluss auf diese Körner, doch kann ich über ihre Natur nichts Näheres angeben, wenn ich auch glauben muss, dass sie einer rückgängigen Metamorphose der Kerne angehören.

Die Eitermassen auf der Linse, so wie die grösseren Klumpen am Boden der Glaskörperhöhle, bestanden nur aus dicht gedrängten Eiterkörperchen, zwischen denen sich nur selten eine spärliche Zwischensubstanz fand. Die Eiterkörperchen waren ziemlich gross, hatten dunklen Inhalt, meist einen oder mehrere Kerne; die $Z$ wischensubstanz war netzförmig angeordnet und wurde in Essigsäure durchsichtig. Mutterzellen oder ästige Zellen liessen sich in dem Eiter nicht finden, dagegen einzelne Elemente der Retina und besonders Stäbchen, welche in kleine Stücke gebrochen, sonst aber unverändert waren.

Die Hyaloidea war also trichterförmig abgelöst, haftete aber noch fast ringsherum an der zonula Zinnii; sie enthielt noch ziemlich consistenten Glaskörper, in welchem viele Eiterkörperchen und in hohem oder niedrigem Grade verfettete Epithelien der Hyaloidea schwammen. Die structurlose Membran der Hyaloidea zeigte gar keine Veränderung, aber es sassen auf ihr nur noch sehr vereinzelte Epithelien, welche auch schon fettigen Zerfall und Umbildung in die sogenamnten Körnchenzellen zeigten. - Die Retiua war an manchen Stellen kaum verändert, an anderen dagegen, und besonders in der Nähe jenes Eiterklumpen, hatte sie den innigen Zusammenhang ihrer Bestandtheile verloren, 
die Elemente waren sehr leicht isolirbar; um jedes Präparat herum sah man sehr zahlreich jene hyaline Schleimkugeln, welche oft noch eine zweite enthielten und zuweilen glänzende Punkte zeigten. Stäbchen, innere und äussere Körnerschicht waren normal, auch die Radialfasern und die Nervenzellen waren noch nicht der Entartung ihres Inhaltes unterlegen, nur die Kerne derselben hatten zum Theil die länglich-runde Form verloren, waren vergrössert und dreieckig geworden. Die Kerne der Radialfasern schienen ebenfalls in einer gradlinigten Schicht $z$ wischen granulöser und innerer Körnerschicht zu liegen. Die Fasern des Opticus, doppelt und einfach contourirte, liessen keine Veränderung erkennen, ausser den Gerinnungen des Markes in den ersteren. Ebenso fand sich die Ausbreitung der limitans in der gewöhnlichen Weise.

Die Zellen des Chorioideaepithels waren ziemlich regelmässig sechseckig und nur einzelne überschritten die normale Grösse, das Pigment lag in allen ganz am Rande der Zelle und bildete einen ziemlich schmalen Saum, die helle Mitte wurde dadurch sehr gross, in ihr fand sich immer ein ziemlich grosser oder zwei Kerne, doch habe ich keine Theilungsvorgänge verfolgt. Das Stroma der Chorioidea war überall von grossen lïnglichen und kleinen runden Kernen erfüllt, die ersteren gehörten den spindelförmigen Faserzellen an, die die letzteren gingen durch leicht zu verfolgende Theilungsvorgänge aus den länglichen Kernen hervor, lagen aber frei im Gewebe zwischen den Zellen und mussten daher wohl als erste Stufe der Eiterkörperchen bezeichnet werden, sie enthielten meist ein Kernkörperchen. Die Pigmentzellen des Stromas waren ungeändert, ebenso die Nerven und grosse Gefässe begleitenden Bindegewebszïge, welche das Stroma durchsetzten.

Die Iris nahm an diesen Veränderungen keinen Theil.

Wenn ich es unternehme, die Resultate dieser fünf Beobachtungen zusammenzustellen, so kann es nicht mein Sinn sein, für alle Einzelheiten eines so sehr verwickel- 
ten Processes eine Norm aufstellen zu wollen; aber alle fünf Fälle stimmen so sehr auch in den Nebenumständen übercin, dass ich doch glaube, einige Umrisse der Eiterbildung im Innern des Auges geben zu können. Meine Resultate verwickeln mich leider in eine mir sehr unangenehme Polemik, aber trotzdem habe ich auch nicht im Geringsten von ihnen abgehen können, da die wiederholte Untersuchung sie mir völlig bestätigte.

Zur besseren Uebersicht halte ich es für das beste, die einzelnen Gewebe des Auges nach ihrem Antheil und Schicksal in der Eiterbildung von einander zu trennen. In allen Fällen war die erste Ursache der Eiterbildung bedeutende Verwundung und Quellung der Linse ohne Verletzung der äusseren Augentheile. Die Beobachtungen habe ich so niedergeschrieben, wie ich sie machte, ohne nach den später verbesserten Ansichten in sie hineinzucorrigiren.

1. Entstehung des Eiters in der Glaskörperhöhle und Verhalten der Chorioidea.

(Fig. 6.)

Die Resultate der Untersuchung auf das menschliche Auge zu übertragen, nehme ich durchaus keinen Anstand, da ich absolut keinen Unterschied zwischen dem Auge des Kaninchens und dem des Menschen kenne, ausser in unwesentlichen Nebendingen. - Es schien endlich, als wäre man nach langem Streite zu einer Einigkeit über die Structur des Glaskörpers gelangt, indem man ihm jede Textur absprach und für ein cystenähnliches Secretionsproduct von der Chorioidea erklärte, umhüllt von einer structurlosen Membran. Da sind ganz vor Kurzem plötzlich von zwei Seiten spindelförmige Zellen entdeckt, welche durch Eiterbildung zum Vorschein gebracht, denselben in allen Richtungen durch- 
ziehen sollten. Unbekannt mit jenen Angaben, glaubte ich auch im 4. Falle diese schon so oft gesuchten Zellen entdeckt zu haben; allein bei näherem Nachforschen faud ich bald, dass diese ästigen Zellen Nervenzellen der Retina waren. Die Abbildung Schweiggers*) ist meinen damaligen Zeichnungen (Fig. 4a.) sehr ähnlich; dann aber muss ich die Untersuchungsmethode Schweiggers, was die Untersuchung des Fiters anbetrifft, für ganz unpassend erklären, da starke Lösungen von chromsaurem Kali die Eiterkörperchen so verändern und solche Gerinnungsprodukte liefern, dass eine sichere Untersuchung kaum möglich ist. Dieser Vorwurf trifft auch zum Theil die Untersuchungen von C. O. Weber, ${ }^{* *}$ ) welcher übrigens wiederholt die Fpithelien der Hyaloidea und ihre Veränderungen zeichnet, sowie die Möglichkeit ciner Verwechselung zugiebt. Ich muss also nach strenger Prüfung meiner Beobachtungen bei rer früheren Ansicht über die Textur des Glaskörpers verharren und behaupten, dass er, ähnlich wie Cysten, aus einer structurlosen Meubran mit dem von mir nachgewiesenen Ejpithel und einem schleimigen Inhalt ohne zelligen Bau und ohne fächrige Scheidewände besteht.

Grobe Verletzungen des Glaskörpers bluiben, wie es die Erfahrung der alten und neuen Zeit häufig genug erwiesen hat, immer ohne alle Folgen, ausser wenn auch zugleich die Augenhäute sehr verletzt sind oder die Linse in bedeutender Weise zerstückelt wurde. Dieser Unstand wurde in den vorliegenden Fällen immer zur Eiterbildung benutzt, die Quellung der Linse hat stets Chorioiditis und Iritis zur Folge. Blutergüsse habe ich in keinem der fünf Fälle beobachtet. Bei der ersten

*) A rehiv für Ophthalmologiv. VII. 2. Sub. IlI. Fig. 1.

**) Virchow's Archiv für pathologische Anatomie. XIX. 3 u. 4. 
Entstehung des Eiters bildet sich ein rundlicher Eiterklumpen am Boden der Glaskörperhöhle innerhalb oder ausserhalb der Hyaloidea; mit zunehmender Eiterbildung füllt sich die Höhle nach und nach mehr, so dass der obere Theil derselben immer bis zuletzt frei bleibt; schon diese Art der Eiteransammlung spricht eigentlich absolut gegen die Zellen des Glaskörpers; wenn Eiterkörperchen specifisch schwerer wie die Glaskörperflüssigkeit sind, weshalb senken sich nicht die präexistirenden Kerne der Zellen, aus denen sie entstehen sollen ebenfalls? Ein vielleicht noch grösseres theoretisches Bedenken gegen jene fraglichen Zellen erhebt sich von Seiten der Iris, welche ich für diese Untersuchung zur Chorioidea hinzurechne. Da diese erwiesenermassen den Eiter in der vorderen Kammer bildet, da nun ferner im hintereu Augenabschnitt sich eine ihr völlig analoge Membran befindet, weshalb soll man zu sonst nicht sichtbaren Zellen seine Zuflucht nehmen? Die Hyaloidea scheint mir nach Allem für Eiterkörperchen durchdringbar, jedenfalls wird sie durch den Eiterungsprocess bald von der Retina abgelöst, von der zonula Zimrin losgerissen und in kleine Stücke zersprengt; die Plattenepithelien erleiden dabei fettige Degeneration und gehen wahrscheinlich auf diesem Wege zu Grunde, während die Glasmembran auch in ihren Fetzen ungeändert bleibt. In den Eitermassen habe ich nur Eiterkörperchen von verschiedener Gestalt gesehen, nie Mutter-oder Spindelzellen.

Im Ganzen stimmen meine Befunde völlig dem V. Falle der Beiträge zur anatomischen Klinik der Augenkrankheiten *) überein. Schweigger, der diesen Fall mikroskopisch untersucht hat, fand Eiterkörperchen

*) Archiv für Ophthalmologie. Bd. VI. 2. 
im Glaskörper, in der Retina und in der Chorioidea und schliesst unter Annahme der Glaskörperzellen auf citrige Entzündung aller drei Gebilde. Meine Beobachtungen haben auch in allen drei Geweben Fiterkörperchen ergeben, allein dem Schlusse Schweiggers kann ich nicht folgen, da im Glaskörper und Retina Elemente fehlen, aus denen Eiterkörperchen entstehen können. Nach meincr Ansicht erfolgt die Bildung des Eiters im Innern des Auges, wenn kein Durchbruch von aussen erfolgt ist, immer von der Gefässhaut des Auges aus, der Chorioidea und der Iris. Keine andere Membran innerhalb der Sclera enthält Bestandtheile, aus denen sich die massenhafte Bildung der Eiterkörperchen erklären liesse. Freilich verkenne ich gar nicht, dass der Nachweis des ganzen Processes nun in einer Richtung viel schwieriger wird, da nun nicht allein die Bildung der Eiterkörperchen, sondern auch der ganze Weg, welchen sie bis in die Glaskörperhöhle durchlaufen müssen, $z u$ verfolgen und $z u$ erklären ist.

Die Stromazellen der Chorioidea sind meinen Bcobachtungen nach diejenigen Zellen, welche die Bildung der Eiterkörperchen vermitteln. Man sieht nach erfolgter Reizung die Kerne der pigmentlosen Stromazellen sich vergrössern, dann sieht man zwei Kernkörperchen in dem Kerne und nun beginnt die Einschnürung der Kernmembran, indem sich entweder zuerst der Inhalt des Kerns und dann erst die Membran (Fig. 6 a und f), oder Membran und Inhalt zu gleicher Zeit abtrennen (Fig. 6 c). Der Erfolg der Abschnürung ist, dass zwei runde Kerne, jeder meist mit einem Kernkörperchen, in einer /elle liegen. Nie habe ich mehr als zwei Kerne in einer Zelle gesehen, und muss daher annehmen, dass nur diese Zweitheilung stattfindet und jene grossartige Kerntheilung, wie man sie in der Cornea so leicht sieht, 
in den Zellen der Chorioidea nicht vorkommt. Dieselben Veränderungen erfolgen in den Muskelfaserkernen der Gefässhaut und führen ebenso zur Theilung der Kerne. Dagegen bleiben die pigmenthaltigen ästigen Zellen im Stroma der Chorioidea völlig unbetheiligt. Der Weg nun, welchen diese getheilten Kerne bis in den Glaskörper zu durchlaufen haben, ist sehr verwikkelt und es steht durchaus nicht in meiner Macht, alle Unklarheiten desselben zu lichten oder zu vermeiden. Zunächst muss ich meine Ansicht dahin aussprechen, dass ich die Eiterkörperchen nicht für Zellen, sondern für Kerne halte und ihre sogenannten Kerne für Kernkörperchen. Obgleich die Entstehung derselben aus Kernen überall aufgesucht und bewiesen wird, vermisse ich doch ein klares Aussprechen dieses Satzes. Das verschiedene Verhalten der Membranen gegen Reagentien kann durchaus nicht als Beweis gegen diese Ansicht angeführt werden, da die Kerne in dieser Theilung bedeutende chemische Veränderungen erleiden. Ueberall sieht man die Eiterkörperchen aus Kernen entstehen, ohne dass sich die Zellenmembranen an der Theilung betheiligen, man kann immer nur die eine Membran um dic Eiterkörperchen entdecken; so erscheint die Definition derselben als getheilte Kerne eigentlich als natürliche Sache, wenn man nicht von Anfang herein sich gewöhnt hätte, dieselben als Zellen zu betrachten. Die Kerne der Stromazellen theilen sich also und bilden nun Eiterkörperchen, hier fehlt mir gleich der Anfang des Weges, welchen sie zurücklegen müssen, nämlich wie sich die Zellenmembranen bei dem Processe verhalten. Man sieht, wenn die Eiterung weiter fortgeschritten ist, in der Chorioidea nur noch Eiterkörperchen dicht gedrängt aneinander und zwischen ihnen sind gar keine Reste der Zellenmembranen zu finden. Diese hochgradige Verän- 
derung beschränkt sich aber auf umschriebene Stellen und es gehen dann diese Partieen in andere allmälig über, wo der fasrige Bau des Chorioidealstromes noch deutlich erkennbar ist, aber zwishen den Zellen, deren Kerne schon fortschreitende Theilungsvorgänge zeigen, liegen jene runden getheilten Kerne frei ohne zugehörige Zelle. Jedenfalls betheiligt sich also die Zellenmembran nicht an der Theilung, sondern geht auf irgend eine Weise zu Grunde; die Kerne werden dadurch frei und stellen Eiterkörperchen dar.

$\mathrm{Ob}$ es bei dieser einfachen Kerntheilung bleibt oder ob die getheilten Kerne sich wieder theilen können, habe ich nicht bestimmen können, doch bedarf es wohl der letzteren Annahme nicht, um die grosse Menge des gebildeten Eiters zu erklären, da die bedeutende Zahl der Stromazellen und die beträchtliche Vergrösserung der Kerne dazu vielleicht ausreichen. Uebrigens zählen ja auch die Kerne der Muskelfasern mit. Nur die Bindegewebskörperchen der Bindegewebszüge, welche die grösseren Nerven und Gefässe begleiten, halten sich lange Zeit völlig unbetheiligt, doch zuletzt verfallen sie ebenfalls dem gemeinsamen Schicksale und man sieht ihre Kerne vergrössert und getheilt.

Die Kerne verlassen also ihre Zellen und liegen frei im Stroma. Man muss annehmen, dass so wie der Kern die Zelle verlassen hat, diese aufhört zu functioniren, es ist damit der erste Schritt gethan zur Verödung der Chorioidea; denn in derselben Weise, wie die Eiterung in jedem anderen Organe zur Zerstörung und Atrophie führt, wird sie auch hier zum Untergang der Stromazellen, zur Zerstörung der Gefässwände führen und nur noch Ruinen des früheren Gewebes übrig lassen.

Die getheilten Kerne sind als Eiterkörperchen anzusehen, allein sie sind der Norm derselben noch durchaus nicht gleich, sondern differiren in morphologischer 
und chemischer Beziehung noch sehr bedeutend von ihnen. Sie sind ungefähr halb so gross als die gewöhnlichen Eiterkörperchen, ihre Membranen viel resistenter gegen Wasser und Essigsäure, der Inhalt hängt fest zusammen, erscheint dunkel und undurchsichtig, wird in Essigsäure nicht heller und umgiebt das Kernkörperchen so dicht, dass man es in den meisten nicht erkennen kann; nie findet sich in ihnen mehr, als ein Kernkörperchen. Der Unterschied dieses jungen Fiterkörperchen von dem ausgebildeten ist so ungeheuer, dass nach der Bildung desselben aus den Zellenkernen und dem dem Austreten aus der Zelle eine sehr bedeutende Weiterentwicklung desselben anzunchmen ist. Ich halte gerade für diese Beobachtung keinen Ort so passend, als die Gefässhaut des Auges, da hier nur einfache Theilung der Kerne und rasches Verlassen der Zelle sich findet und also vielleicht die Weiterentwickelung bedentender sein muss, als in anderen Organen. Von den Fiterkörperchen in der Chorioidea, zu denen in der Glaskörperhöhle lässt sich ein stufenweiser, allmäliger Uebergang beobachten, welcher jeden Zweifel an der Identität vernichtet. So bedentend übrigens auch dic Veränderungen sind, so können sie durchaus nicht Wunder nehmen, da wir täglich die Eiterkörperchen in den indifferentesten Flüssigkeiten so energische Reactionen machen sehen und die Eiterkörperchen der Chorioidea in verschiedene Organe und Flüssigkeiten gerathen. An diesen Veränderungen bis zur völligen Ausbildung nehmen alle Theile der Eiterkörperchen Antheil. Die Membran nimmt an Dicke $a b$ und verliert ihre Resistenzfähigkeit gegen Reagentien, sie wird nun zu einer dünnen Membran, welche sich rasch in Wasser auflöst, cbenso verliert der Inhalt seine dichte Cohärenz und dunkles Aussehen, wird hell und durchsichtig und nimmt 
dabei bedeutend an Masse zu, so dass das Eiterkörperchen endlich seine gewöhnliche Grösse erlangt. Durch die Umsetzung des Inhaltes wird dann das Kernkörperchen jedesmal sichtbar und man bemerkt bei weiterer Entwicklung immer zwei und mehrere Kernkörperchen, doch konnte ich über den Modus dieser Vermelirung nicht zur Bestimmtheit gelangen. Dass diese Veränderungen alle auf chemischen Umwandlungen beruhen, leuchtet wohl von vornherein ein und wie leicht und rasch Eiterkörperchen solchen unterworfen sind, haben alle Untersuchungen von jeher dargethan. Der allmälige Fortschritt der getheilten Chorioideakerne in ausgebildete Fiterkörperehen innerhalb der Glaskörperhöhle lässt sich Schritt vor Schritt verfolgen und es ist mir kein Zweifel mehr daran geblieben. Die übrigen Theile der Chorioidea werden durch die Fiterbildung mehr oder weniger beeinflusst. Die ästigen Pigmentzellen des Stromas bleiben am längsten ungeändert und resistent, natürlich leilen sie auch von allen Theilen der Chorioidea am allerwenigsten, da sie in den äussersten Schichten liegen. Bei fortgeschrittener Eiterbildung besonders in den äusseren Zellen scheinen sie durch Zerstörung ihrer Membranen zu Grunde zu gehen; es bleiben an ihrer Stelle nur Pigmenthaufen zurück, in welchen die Stelle, wo früher der helle Kern lag, noch durch Pigmentmaugel erkennbar ist, natürlich beschränkt sich diese Zerstörung nur auf einen kleinen Umkreis und beginnt, wie es scheint, mit der Membran der Aeste. Die Gefässe der Chorioidea nehmen an Lumen bedeutend $z u$ und vermehren sich wahrscheinlich auch, doch habe ich die Neubilbildung derselben nicht verfolgt; die sie begleitenden Bindegewebszüge bleiben, wie schon erwähnt, lange unverändert, erst spät gehen die Zellen derselben Kernvermehrung ein und dadurch ist meiner Ansicht nach der Beginn des Unterganges der Gefässe eingeleitet. 
Von vorn herein sondern aber die Gefässe ein faserstoffiges Exsudat $a b$, welches gleich durch alle Theile des Auges diffundirt, wie dies Schweigger sehr gut nachgewiesen hat (l. c.). Es ist hier vielleicht für das Kaninchenauge, als besondere Eigenthümlichkeit festzuhalten, dass man in ihm nie flüssigen Eiter findet, sondern dass die Zwischensubstanz zwischen den Zellen immer netzförmig fasrig ist, im vorderen wie im hinteren Augenabschnitt. An eine Gerinnung nach dem Tode ist durchaus nicht zu denken, da die Eitermenge nie das Nivelliren der Flüssigkeiten zeigt. Ob freilich hierin ein absoluter Gegensatz gegen das menschliche Auge zu suchen ist, bleibt mir sehr zweifelhaft, da man auch beim Menschen den Eiter im Auge so häufig aus fasriger Zwischensubstanz bestehen sieht, wie die Bewegungslosigkeit und Untersuchung von Hypopyen Iehrt.

Die structurlose Membran der Chorioidea tritt beim Kaninchen ohne Mächtigkeit auf, ich muss sie nach Analogie nicht für ein Hinderniss der Eiterpassage erklären, sondern glaubte, dass die Eiterkörperchen durch sie hindurch treten könneli. Zuerst also tritt das PigmentFpithelium den Eiterkörperchen entgegen. Die Zellen dieser Epithelialschicht sind während der Vorgänge im Stroma bedeutende Veränderungen eingegangen; viele von ihnen vergrössern sich, geben ihre regelmässig sechseckige Form auf, werden ausgebuchtet und pressen kleinere Zellen zwischen sich zusammen, so dass der helle Zwischenraum zwischen den Zellen verschwindet. Dabei zerstreut sich das Pigment in ihnen dicht an den Umfang der Membran, um welchen es einen schmalen braunen Streifen bildet, während der grosse mittlere Theil der Zelle hell durchscheinend wird und öfters zwei Kerne enthält, doch glaube ich nach Allem nicht, dass eine pathologische Kerntheilung stattfindet. Durch die Ausdehnung wird die Membran verdünnt und bietet den vor- 
gedrängten Fitermassen nur ein leichtes Hinderniss dar, einige der vergrösserten 7ellen werden zerstört, ihr Pigment nach allen Seiten hin diffundirt, natïrlich am meisten mit dem Strom der Masse gegen die Mitte des Auges hin, die Kerne der Pigmentzellen liegen nun ebenfalls frei. Durch solche Lücken treten die literkörperchen, welche einzeln auch zwischen den Zellen hindurch hätten passiren können, in Masse zwischen Chorioidea und Retina, sie bilden hier, durch letztere etwas zurückgehalten, dünne Schichten, welche nur aus kleinen Eiterkörperchen und fasriger Zwischensubstanz bestehen.

Wenn es nun auch scheint, als gewährte ihnen die Retina ein gewisses Hinderniss, so treten sie doch geradezu durch dieselben hindurch; man sieht die Eiterkörperchen zwischen den Flementen der Retina überall zerstreut liegen. Dadurch verlieren die Bestandtheile, derselben ihre Cohärenz untereinander, sie werden allmälig selbst mehr und mehr von dem fortschreitenden Strome der Eiterkörperchen losgerissen und mit fortgetricben in die Höhle des Glaskörpers. Dic fester zusammenhängende limitans wird dabei zerrissen und in Fetzen überall umher zerstreut, die Nervenzellen der Retina, Radialfasern und Stäbchen finden sich oft tief in der Höhle des Glaskörpers zwischen den Eiterkörperchen; doch ist diese Zerstörung durchaus nicht überall gleich. Dass an manchen Stellen der Retina der Durchtritt den Eitermassen schwerer wird, dafür sind die Anhäufungen derselben hinter der Retina auch in späterer Zeit und die relative Unversehrtheit mancher Retinastellen genügende Bürgen. Es wäre für die Eitermenge noch ein anderer Weg aus der Chorioidea in die Glaskörperhöhle möglich, und zwar durch Ablösung der Retina von der zonula Zinnii; dass dieser Weg nicht der gewöhnliche ist und auch nur für einen Theil der Eiterkörperchen gelten könnte, zeigt die Anlagerung der Re- 
tina an die Chorioidea, welche nur sehr selten aufgegeben wird. Durch alle diese Vorgänge erklärt sich der verschiedenartige Zusammenhang der Retina und Chorioidea, welchen wir in den einzelnen Fällen begegnet sind, sehr leicht; bald hingen sie fest zusammen und konnten nur so getrennt werden, dass Stücke der einen Membran an der anderen hängen blieben, bald waren sie für eine kleine Stelle durch eine Eiterschicht völlig von einander getrennt.

Zuletzt gelangen also die Kiterkörperchen in die Höhle des hinteren Augabschnittes; es wird dadurch jedesmal die Hyaloidea von der Retina abgelöst, anfangs scheint sie noch einen zusammenhängenden Sack zu bilden, allein bald wird sie auseinander gerissen und man findet nur noch zerstreute Stücken von ihr. Uebrigens ist vielleicht die structurlose Membran für Eiterkörperchen permeabel, denn man findet hàufig Eiterkörperchen in ihr, wenn sie auch noch einen zusammenhängenden Sack bildet. Der Glasmembran hängen immer nur noch einzelne, in fettiger Degeneration begriffene Epithelialzellen an. Der Glaskörper selbst wird sehr bald flüssig und trübe, verliert seine klebrige Cohärenz und Durchsichtigkeit, man findet in ihm Epithelialzellen der Hyaloidea schwimmen, welche mehr oder weniger verfettet den Uebergang in Körnchenzellen sehr gut zeigen. Mit zunehmender Eitermenge verschwindet der Glaskörper allmälig, wahrscheinlich durch Resorption der flüssigen Bestandtheile. Die grösstentheils in Körnchenzellen verwandelten Plattenepithelien der Hyaloidea aber bleiben bestehen, ihr Kern verschwindet, vielleicht geht auch bei weiterem Fortschritt der Degeneration die Membran der Zelle verloren. So ist der Weg der Eiterkörperchen beendet; die Eitermasse, bestehend aus der netzförmigen Zwischensubstanz und Eiterkörperchen, erfüllt den ganzen hinteren Augenabschnitt, wo ihr die vorhandenen 
Gewebstheile Raum lassen, dringt sie in dieselben ein und zwingt sie zu Metamorphosen.

Der Antheil, welchen die Iris an der Eiterbildung nimmt, verdient noch eine besondere Betrachtung. Die Iris betheiligt sich nicht immer in gleicher Weise, zuweilen (und bei weiterem Fortschritt der Eiterung wird dies wohl jedesmal der Fall sein) ist sie ebenso verändert, wie die Chorioidea, zuweilen (mehr am Anfang des Processes) sind die Veränderungen sehr gering und beruhen nur hicr und da in Vergrösserung und Theilnng der Kerne. Es sind übrigens in den Kernen der Muskelzellen die Theilungsvorgänge am leichtesten zu verfolgen. Wenn die Kerntheilung in der Iris lebhaft vor sich geht, so findet man auf der vorderen Oberfläche der Iris Eiterkörperchen in einer anfangs feinen, später dickeren Schicht liegen und bald bildet sich in der vorderen Kammer ein fest zusammenhängender Pfropf, welcher oft nur wenige Eiterkörperchen und bald mehr, bald weniger Faserstoff enthält. Durch diese Schicht wird natürlich die Farbe derreits sehr verändert. In seltneren Fällen findet sich nur ein Niederschlag auf der hinteren Wand der Cornea, welcher diese in Form einer sehr wechselnd dicken Schwarte überzieht; er besteht meistens fast nur aus geronnenem Faserstoff, in welchen nur hier und da ein einzelnes Eiterkörperchen eingebettet ist. - Auch in der vorderen Augenkammer war der Eiter nie flüssig, ruhte sogar nur selten alm Boden derselben. Dieser Befund widerspricht durchaus nicht den Beobachtungen an Menschen, wenn auch der allgemeinen Annahme über die Consistenz der Hypopyen. J unge*), dessen Untersuchungen ich vollkommen bestätigen kann, fand meist die Grundsubstanz der Hypopyen fest; wiederholt habe ich eben dem Auge entnommene Hypopyen aus dersel-

*) Archiv für Ophthalmologie V 2. 
ben fasrig-netzförmigen Zwischensubstanz und Eiterkörperchen in sehr verschiedenem Verhältniss zusammengesetzt gefunden, ohne annehmen zu können, dass die Gerinnung im Momente nach der Operation entstanden wäre. Noch kürzlich zog Herr Hofrath Baum hei einer Iridectomie wegen Iritis eine fest der ganzen Cornea anliegende Schwarte aus der vorderen Kammer, welche nach seiner Untersuchung nur aus Faserstoff und wenigen Eiterkörperchen bestand. - Zuweilen kann aber auch ohne besondere Betheiligung der Iris Eiter in der vorderen Kammer sich finden und zwar, wenn die vordere Kapselwand der Linse durch die Operation künstentfernt oder gesprengt ist. Die Pupille ist in diesen Fällen immer sehr eng, allein die Eitermassen im hinteren Augenabschnitt öffnen sie wieder und treten in die vordere Kammer ein; doch ist anzunehmen, dass schon durch das Andrängen dieser Massen die Iris selbst bald nachher in den Eiterbildungsprocess hineingezogen wird. Mögen nun diese Eiterpfröpfe im Pupillargebiete aus der Glaskörperhöhle oder aus der Iris stammen; immer hängen sie fest zusammen und senken sich nur sehr langsam, d. h. nach mehreren Tagen, gegen den Boden der vorderen Kammer. In anderen Fällen dagegen bildet der Eiter einen flockigen Niederschlag auf der Iris, welcher sich schichtenweise übereinander lagert, so dass man wohl annehmen kann, dass die Eiterkörperchen sich erst im humor aqueus suspendiren und dann nach und nach, wie sie entstanden sind, wieder auf die Iris senken. Uebrigens ist es doch eine sehr merkwürdige Sache, dass der Eiter aus der Iris die Tendenz hat, nach vorn zu wandern; es ist dies schon daraus ersichtlich, dass die Epithelzellen der Uvea nur äusserst geringe Veränderungen eingehen, gegenüber dem Pigmentepithel der Chorioidea. Die Pigmentzellen des Irisstroma sind ebenfalls sehr resistent. 
Wenn wir noch einmal die Bestandtheile des im hinteren Augenabschnitt befindlichen Eiters recapituliren, so ist die Masse zusammengesetzt aus Eiterkörperchen und netzförmig angeordnetem liaserstoff, dann aber finden sich in ihr Reste der Hyaloidea, kleine und grosse Stücke der unveränderten structuriosen Membran und fettig degenerirte Epithelialzellen, dann Theile aus allen Retinaschichten, durchlöcherte Fetzen der limitans, Nervenzellen mit langen Aesten, abgerissene Radialfasern, Theile von Stäbchen und zuletzt Pigmentmolecüle aus den zerstörten Zellen des Chorioideaepithels. Die später zu besprechenden Elemente der Linse sind hier noch nicht erwähnt. Weit einfacher sind allerdings die Eitermassen der vorderen Kammer zusammengesetzt, da hier in die Elemente des Eiters sich höchstens einige Linsenfaseru verirren.

Die Art der lintstehung und des Weges des Eiters glaube ich auf diese Weise in den Grundzügen angegeben zu haben, es fragt sich nun, ob sich einige Angaben finden für die Dauer und den Verlauf des ganzen Prozesses. In 5. und 1. Falle lagen am 6. und am 10. Tage nach geschehener Linsenverwundung schon erbsengrosse Literklumpen am Boden der Glaskörperhöhle, es war also die Bildung und Wanderung der Eiterkörperchen so weit fortgeschritten, dass eine so grosse Menge von Fiterkörperchen in der Chorioidea gebildet und durch die Retina hindurch gewandert war; und ebenso lag im 1. Falle am 10. Tage eine grosse Eiterschwarte an der Cornea. Demmach geht die Eiterbildung in Chorioidea und Iris gleich rasch vor sich und ist so massenhaft, dass sie schon nach sechs l'agen die Eiter bildenden Membranen an Masse übertrifft. Der 3. Fall, am 12. Tage nach der Verletzung untersucht, ergab, dass die Hälfte der hinteren Bulbushälfte mit Eiter erfüllt war. Im 4. und 3. Falle, am 16. und 25. Tage nach 
erfolgter Verletzung, erfüllte die Eitermasse den ganzen hinteren Augenabschnitt, ohne dass irgend ein übrig gebliebener Theil des Glaskörpers hätte gefunden werden können. Die Eiterbildung brauchte also weniger als sechs Tage bis zu beträchtlichem Lrguss in die Glaskörperhöhle und nur sechszehn bis fünfundzwanzig bis zur völligen Erfüllung derselben. Dabei verlor der Bulbus nur sehr wenig von seiner Prallheit, war also ziemlich vollständig erfüllt. Da in allen diesen Fällen dieselbe Ursache, Quellung der Linse, vorlag, so wird auch in allen ziemlich dieselbe Raschheit des Ganges vorauszusetzen sein. Diese ungeheure Production, gegenüber dem Volumen der Gefässhaut, muss auf das Höchste in Erstaunen setzen, während allerdings die Menge der Chorioidea - und Iriszellen und die Grössenzunahme der Eiterkörperchen dies Erstaunen wieder einigermassen löst. Uebrigens sind vielleicht durch die genaue Kenntniss der Chorioidea und die Zurückhaltung des Eiters, in der Bulbushöhle nirgends, an keiner Stelle des Körpers so genaue Daten, wie hier, zu erlangen.

Eine weitere Frage ist, zu welchem Ziele die Eiterbildung im Auge führt; in den gegebenen Fällen liegt keine bestimmte Antwort darauf vor, da sie alle in der ersten Periode derselben untersucht sind. Die klinische Antwort ist sehr einfach: zur Atrophie des Bulbus; die Materialien zur Atrophie finden sich, was die vorliegenFälle betrifft, in der Zerstörung der Stromazellen der Chorioidea und Iris und des Bindegewebes ihrer Gefässe, in der Zerstörung der Retina und des Glaskörpers. Aber bis zum 25. Tage des Processes lag noch keine directe Andeutung einer rückgängigen Metamorphose desselben vor. Dass der Eiter nur einer rückgängigen Metamorphose fähig ist, haben alle Beobachtungen bewiesen, doch in vorliegenden Fällen war nichts davon zu bemerken; wenn man nicht, wie ich eigentlich geneigt bin, anneh- 
men will, dass das Klar- und Durchsichtigwerden des Inhaltes der Eiterkörperchen für die Einleitung der rückgängigen Metamorphose anzusehen ist. I)ie oft gesehenen Körnchenzellen stammen nicht vou Eiterkörperchen, sondern von dem Epithel der Hyaloidea ab.

\section{Verhalten der Retina wahrend des Eiterungs - Processes.}

(Fig. 4 und 5).

Der Beschrcibung der Veränderungen der Retina während des Eiterungsprocesses muss ich bei den jetzt so sehr differirenden Ansichten, um allgemein verständlich zu werden, einige Bemerkungen über meine Ansicht von dem Baue der Netzliaut vorherschicken. In Allgemeinen halte ich an dem von IIeinrich Müller*) angegebenen Bau der Retina, an seiner Schichteneintheilung fest. Was die feinere Structur der Stäbchen anbetrifft, so kann ich die Angaben, welche ich über ihre Zusanmensetzung beim Frosche gemacht habe, nach wiederholten Untersuchungen an Wassersalamandern bestätigen und zweifle nicht, dass die Existenz des centralen Fadens auch bei höheren Thieren nachgewiesen werden wird, sobakd man frisches Untersuchungsmaterial erhalten kamn.* ${ }^{*}$ ) Die Behauptung von Max

*) Zeitschrift für wisscinschaftliche Zoolugic Band VIII Heft 1.

**) Archiv für Ophthalmologic V. 2. pag. 101-111. Da es mir wahrscheinlich nicht wieder vergöınt wird, auf diesen Punkt zurückzukommen, so sei es mir hier erlaubt zu bemerken, dass es mich ausserordentlich gefreut hat, in der letzten Zeit von zwei Seiten Bestätigungen meincr Angaben crhalten zu haben. W. Krause (anatomische Untersuchungen pag. 56) hat diese Structur nicht beim Frosch, sondern in den Zapfen der Vögel gesehen, wie ich schon früher flüchtig angegeben hatte. Dagegen habe ich so eben durch die Güte des Herrn Hufrath Henle das nüchste Heft der Zeitschrift für rationelle Pathologie im 
Schultze*), dass ein Theil der Radialfasern bindegewebiger Natur sei, ist meiner Ansicht nach noch nicht erwiesen, da ich der Form seines Schlusses: dass, da die limitans und die ihr anhängenden Theile der Radialfasern zum Bindegewebe zu rechnen wären, auch der äussere Theil derselben bindegewebiger Natur sein müsse, nicht folgen kann, auch seine Ansicht über die Natur der Nervenzellen in der Retina, cellulas gangliosas nihil aliud esse, quam tumores cylindrorum axis nucleo instructos, nicht theilen kann. Uebrigens kann ich Schultze's Angaben über die Kerne der Radialfasern vollkommen bestätigen, wie dies auch Manz thut. Auch ich habe eine solche Kernschicht zwischen innerer Körnerschicht und granulöser Schicht gesehen und es wird nun, wenn es sich bestätigt, dass die Kerne immer in einer Schicht liegen, die innere Körnerschicht in zwei Theile zu theilen sein; der äussere, weit grössere Theil wird aus den bekannten inneren Körnern zusammengesetzt, welche übrigens nicht, wie Heinrich Müller angiebt, in der Axe der Radialfasern, sondern immer seitlich von derselben, als rundliche Ausbuchtungen, liegen und nie einen Kern enthalten; der innere kleinere Theil wird von den Kernen der Radialfasern gebildet, welche innerhalb einer dickeren Anschwellung der Fasern liegen, länglich oval sind und ein deutliches Kernkörperchen enthalten. Vielleicht bin ich übrigens nur durch die später zu beschreibenden pathologischen Veränderungen zur sicheren Erkenntniss dieser Kerne gelangt, kann sie aber noch durchaus nicht benutzen, um die Müller'schen Radialfasern in zwei Gruppen zu theilen, wie es Max

Aushängebogen eingesehen, welches (pag. 301) einen meine Untersuchungen völlig bestätigenden Aufsatz von Manz über die Froschretina enthält.

*) Observationes de retinae structura penitiori. 
Schultze will. Seine weiteren Mittheilungen werden vielleicht neues Licht über den noch lange nicht genug durchforschten Bau der Retina verbreiten.

Während des Eiterungsprocesses im Innern des Auges hat also die Retina das Schicksal, dass die in der Chorioidea gebildeten Eiterkörperchen durch sie hindurch in die Höhle des Glaskörpers wandern. Durch diesen Vorgang wird natürlich die seitliche Cohärenz der Retina-Elemente untereinander gelockert, dann die innersten Schichten, später die äusseren von ihr losgerissen und in die Eitermassen hineingesprengt; es sind dies also rein mechanische Continuitätstrennungen, welche an verschiedenen Stellen in sehr verschiedenem Grade stattfinden. Dann aber gehen einzelne, besonders dazu befähigte Theile der Netzhaut noch andere Veränderungen ein, welche zum grössten Theil einer regressiven Metamorphose, zum Theil aber auch einer progressiven angehören, letztere angeregt durch die von der quellenden Linse hervorgerufene entzündliche Thätigkeit.

Die mechanische Trennung der Theile durch die durchtretenden Eiterkörperchen isolirt die einzelnen Elemente von einander und zwar in einer Weise, wie sie menschlicher Präparation nur durch einen seltenen Glücksfall oder durch die Energie und Ausdauer, welche H. Müller und Kölliker angewandt haben, gelingt. Durch diese natürliche Präparation aber ist es sehr leicht möglich, den natürlichen Zusammenhang der Theile, wie er wirklich in der Retina stattfindet, zu erkennen und völlige Gewissheit zu erlangen. Es kommt hierbei zunächst nur auf die Nervenzellen und ihren Zusammenhang an, während allerdings der fast noch feinere $\mathrm{Zu}$ sammenhang des äusseren Korns mit der Stäbchenschicht seiner Natur nach bei diesem Processe zu Grunde gehen muss. Die Aeste der Nervenzellen sind danach beim Kaninchen allerdings nicht so zahlreich, als sie Corti 
beim Elephanten gezeichnet hat, allein ihre Zahl ist doch um Vieles grösser, als sie gewöhnlich angenommen und gezeichnet wird (Fig. 5). Die Aeste sind sehr verschieden dick, die dünnen theilen sich nicht weiter, die dicken sind wenigstens doppelt so breit, als die dünnen, und theilen sich jedesmal, so viel ich gesehen habe, in zwei oder drei gleiche Aeste, so dass annäherungsweise die Dicke der Aeste doch ziemlich gleich ist. Der Uebergang einzelner Aeste in varicöse Nervenfasern wird im Ganzen doch ziemlich allgemein zugegeben und braucht daher hier wohl nicht wieder bekräftigt zu werden; doch leugnet ihn Manz (1. c.) neuerdings wieder, während ich ihn deutlich wiederholt gesehen habe. Ebenso erfahren die Verbindungsäste zwischen den einzelnen Nervenzellen wenig oder keinen Widerspruch, sie sind sehr zahlreich, bald kurz, bald lang, mitunter verbinden zwei Aeste zwei Zellen. Die Hauptschwierigkeit beruht in den Verbindungsästen zwischen Nervenzellen und Radialfasern, welche von $H$. Müller und Kölliker nur mit grosser Vorsicht angenommen wurden, in neuerer Zeit aber von verschiedenen Seiten und auch von Max Schultze geleugnet sind. Dies ist durchaus mit Unrecht geschehen, denn fast in allen Präpäraten habe ich sehr deutlich eine kermhaltige Radialfaser (also Max Schultze's Bindegewebe) oder eine nicht kernhaltige, durch einen verschieden langen Ast mit einer Nervenzelle verbunden gesehen. Diese Aeste sind meist rechtwinklich gebogen (Fig. 5 e.) Einen Unterschied zwischen Radialfasern, welche mit Nervenzellen verbunden sind, und kernhaltigen Radialfasern, welche nur dem bindegewebigen Stützapparat dienen, kann ich also nicht machen.

Nach dieser für die Untersuchung des Zusammenhanges so glücklichen Trennung der einzelnen seitlich cohärirenden Theile folgt aber die Zerstörung der Membran, und zwar beginnt diese an der Limitans und den 
inneren Schichten, während die äusseren mehr zusammenhảngend bleiben und erst später ebenfalls von der Zerstörung ergriffen werden. Die Limitans, eine structurlose Membran, eigentlich ohne jede Dicke, wird in einzelnen Fetzen unregelmässig abgerissen, sie selbst verändert sich ebensowenig, wie alle structurlosen Membranen; die Fetzen sind sehr verschieden gross, mit gradlinigten, eingerissenen Rändern versehen; hier und da sieht man in ihnen kleine viereckige oder unregelmässig geformte Löcher, wahrscheinlich sind die hier ausgerissenen Stücke bei der Trennung der Radialfasern von der Limitans an den breiten Enden der Fasern hängen geblieben. Man findet solche Fetzen weithin durch die ganze Eitermasse zerstreut und sie bleiben immer in derselben Weise völlig ungeändert.

Die Nervenfaserschicht habe ich nicht genau verfolgen können. So lange die Schicht noch nit der Retina zusammenhängt, sieht man ausser der Gerinnung des Nervenmarkes in den doppelt cnntourirten Fasern des Kaninchen durchaus keine Veränderung. Später, wenn die Schicht losgerissen ist, lassen sich keine zusammenhängenden Stücke derselben finden und kleine Stücke der einzelnen Fasern haben das charakteristisch Erkennbare verloren. Dagegen sieht man Nervenzellen, Theile von Radialfasern und von Stäbchen sehr häufig in den Eitermassen des Glaskörpers, einzelne kleine Theile weit zerstreut, grössere meist in Nestern dicht vor der Retina liegend.

Die Veränderungen, welche in den Radialfasern und Nervenzellen eintreten, sind sich sehr ähnlich, ich werde sie daher hier zusammenfassen. Zunächst muss ich noch bemerken, dass ich trotz der vielfachen, in neuerer Zeit erfolgten Angriffe die Zellen der Retina für wahre Ganglienzellen halte. Wenn Manz (1. c.) in der Froschretina keine multipolaren Zellen gefunden hat, so ist 
dieser Umstand nur ein Reweis dafür, dass die Untersuchung der Nervenzellen in der Froschretina ihm eben so schwer geworden ist, wie anderen Beobachtern und auch mir; aber desshalb existiren die multipolaren Ganglienzellen beim Frosche doch eben so gut, wie bei allen höheren Thieren. Grade dadurch wird die Untersuchung der Retina so schwierig, weil bei derselben, wie Heinrich Müller schon so bedeutend hervorgehoben hat, erst die vergleichend-anatomische Forschung sichere Resultate erhält, während die Untersuchung eines Thieres, ja einer Thierklasse, nur zu halben und ungewissen Resultaten führen kann. Weiter muss ich noch eimmal hervorheben, dass ich bis jetzt nach den vorliegenden Untersuchungen und meinen eigenen Beobachtungen das Systeın der Radialfasern zwischen Nervenzellen und Stäbchenschicht eingeschoben halte, und dass mich die in den Radialfasern aufgefundenen Kerne nicht zwingen, dieselben oder nur einen 'Theil dersalben für Bindegewebe zu erklären, ebensowenig wic ich Ganglienzellen des Kerns wegen für Bindegewebszellen ansehen kann.

Die Radialfasern quellen zunächst nach der Continuitätstrenmnng von einander auf, werden breiter, hier und da winklig umgebogen; dabei verlieren sie den gelblichen Schein und den matten Glanz; dann aber benerkt man, dass sich eine Membran und ein Inhalt in ihnen sontert und zwar dadurch, dass die Faser im Innern leicht granulirt wird. Diesc Veränderung ist nicht in allen Theilen gleich, sie ist am stärksten da, wo ein inneres Korn liegt oder in der Ungebung eines Kern; sic tritt dagegen an den Stellen mehr zurück, wo die Faser schmal wird (Fig. 4 a. b. c.). Wenn nun in der Radialfaser ein Korn liegt, hat sie offenbar diesclben Elemente, welche die Nervenzellen haben, nur ist sie lang gestreckt und besitzt nur zwei, höchstens drei Aeste, und zwei von den Aesten sind immer abgerissen. Ich möchte 
dieser Vergleichung nicht von vornherein jeden Werth absprechen. Der Inhalt der Radialfaser, welcher im normalem Zustande den leicht gelblichen Glanz bedingt, ist also nicht an allen Stellen gleich bedeutend; da wo die inneren Körner an den Fasern liegen, ist er gehäuft und bildet dadurch die Ausbuchtung der Membran, das innere Korn; an den dünneren Stellen der Fasern findet er sich dagegen sehr spärlich, ist zuweilen sogar kaum zu entdecken; an den Stellen, wo die Kerne der Radialfasern sich befinden, erreicht die Faser immer ihre grösste Breite, aber der Kern erfüllt sie auch hier ganz, dagegen bleibt die Faser noch eine kleine Strecke nach beiden Seiten hin von der nämlichen Breite und verschmälert sich erst allmälig wieder; in diesen Stellen deutet ebenfalls die Granulirung des Innern grössere Anhäufungen des Inhaltes an. Die Granulirung verliert sich nicht auf Zusatz von Essigsäure. Man könnte die Granulirung auch einfach für einen Zerfall der inneren Theile der sonst gleichmässigen Radialfasern halten, ohne dass ein bedeutender Unterschied zwischen ihnen und den äusseren Theilen zu machen sei. Allein dann wäre es doch höchst wunderbar, dass dieser Zerfall immer nur die innersten Theile beträfe, dass er die dünneren Theile der Fasern weniger betheilige, und endlich spricht das Verhalten der inneren Körner absolut dagegen. Diese Körner, deren Lage zu den Radialfasern ich früher schon erwähnt habe, sind also als einfache Ausbuchtungen der Radialfasern mit Anhäufungen des Inhaltes anzusehen und es schreibt sich daher der lebhafte Glanz derselben. Die Zahl der inneren Körner ist übrigens bedeutend grösser, als die der Kerne, so dass wenn nur ein inneres Korn auf eine Radialfaser käme, viele Fasern ohne Kern sein müssten; aber wahrscheinlich gehören auch mehrere innere Körner zu einer laser. Eine genaue Verfolgung dieser durchaus nicht einfachen Verhältnisse wird gewiss zu bedeutenden Resultaten führen. 
Die Nervenzellen der Retina sind schon im natür. lichen Zustande granulirt, ihr Inhalt daher von dem der Radialfasern etwas unterschieden; die Granulirung der Fasern habe ich nur an den Endigungen der Präparate gezeichnet (Fig. a und c). Die Granulirung ist aber nur die Einleitung zu dem Processe, welcher sich nun in den Nervenzellen und in den Radialfasern gleichförmig geltend macht. Es verliert der Inhalt die feine Granulirung und wird krümlig; anfangs treten in ihm einzelne dunkle, glänzende Punkte auf, welche in Kssigsäure nicht löslich sind; diese vermehren sich, liegen besonders in der Nähe des Kerns und bei den Radialfasern in den Ausbuchtungen der inneren Körner und bilden zuletzt, indem die feine Granulirung wieder völlig verschwindet, den ganzen Inhalt der Zellen und Fasern. Man sieht übrigens während dieser Vorgänge die Nervenzellen nicht in der Weise, wie die Plattenepithelien der Hyaloidea, in Körnchenzellen verwandelt, sondern die Zelle bewahrt im Ganzen noch ein durchsichtiges Ansehen und nur einzelne kleine, dunkel glänzende Punkte liegen in ihr zerstreut, meist in kleinen Haufen um den Kern der Zelle oder an Stellen, wo grössere Aeste abgehen, während grössere Theile der Zellen ganz frei von ihnen bleiben (Fig. 5). Die Radialfasern zeigen um die Kerne herum und in den innern Körnern grössere Anhäufungen dieser glänzenden Körnchen, welche hier eng aneinander liegen, dagegen finden sie sich in dem übrigen Verlaufe der Radialfasern sehr sparsam, nie in Haufen, sondern einzeln, höchstens zn zweien nebeneinander und durch ziemliche weite Zwischenräume getrennt; sie liegen dann immer in der Mitte der Faser. Es sind nun, von dem glatten Aussehen der Radialfasern und der leichten Granulirung der Nervenzellen bis zu den letzt beschriebenen Zuständen die allmäligen Uebergänge leicht zu verfolgen; die ersten Andeutungen finden sich erst 
nach einigen Tagen, während die Elemente noch zur Membran zusammengefïgt sind; die höchsten Grade liessen sich nur in den Fällen entdecken, in welchen die Eitermasse den ganzen Bulbus erfüllte und die Zellen und Fasern zum grössten Theil zwischen denselben lagen. Ohne $Z$ weifel sind diese Vorgänge als fettiger Zerfall des Inhaltes beider Theile aufzufassen und repräsentiren die verschiedenen Stufen desselben. Membran und Kern bleiben frei von demselben.

Es ist dies der degenerative Vorgang, welcher in den Radialfasern und Nervenzellen auftritt; er ergreift den Inhalt beider Theile, auf welchen die Function derselben beruht, und macht sie dadurch functionsunfähig, vernichtet also die Wirksamkeit und Bedeutung dieser beiden Elemente, ohne welche die Aufgabe der Retina, das Vermitteln des Sehens nicht erfolgen kann. Wie diese Degeneration weiter verläuft, habe ich in den vorliegenden lällen nicht weiter verfolgen können, da diese nur den ersten Act der Eiterung darstellen; es ist mir aber im höchsten (irade wahrscheinlich, dass durch ihn, wie in allen Organen durch fettige Degeneration, Resorptionsvorgänge eingeleitet werden, welche den in Fett verwandelten Inhalt der Zellen und Fasern betreffen und allmälig dessen gänzliches Verschwinden vermitteln. Ob dabei ein nicht fettig legenerirter Theil des Inhaltes in ihnen zurückbleibt, vermag ich natürlich nicht anzugeben; aber es werden mir durch diese ganze Annahme die so häutigen Sectionsbefunde von atrophischen Augen erklärlich, in denen Unversehrtheit der Radialfasern und Nervenzellen angegeben und durch die Erfahrung der Untersucher hinreichend verbürgt ist. Es könnten beide Gebilde nach der Resorption des Inhaltes ihre Form und Ansehen erhalten haben und der frühere abgelaufene Vorgang nur vielleicht in geringen Veränderungen des Glanzes, der Völle und der Cohäsion mit den Nachbar- 
gebilden erkennbar gewesen sein, welche jenen Beobachtern, da nur Nebensachen darauf hätten hindeuten können, entgehen müssten. Das Verhalten der inneren Körner, welche bis jetzt immer nur nebenbei erwähnt wurden, möchte ich als Kriterium dieser Hypothese empfehlen. Uebrigens findet dieser Vorgang eine fast völlige Analogie in den später zu beschreibenden Veränderungen der Stäbchen.

Ausser diesen degenerativen Vorgängen finden sich aber noch weitere in den Zellen und Fasern, welche einen ganz verschiedenen Charakter haben. Ich habe schon früher bemerkt, dass ich, obgleich aufmerksam durch die Schrift von Max Schultze,*) auf die Kerne der Radialfasern hauptsächlich erst durch pathologische Vorgänge aufmerksam geworden bin; nur werden die Kerne allerdings durch den Verlust des Glanzes der Faser und die fettige Degeneration des um sie liegenden Inhaltes mehr hervorgehoben und ihre Contour deutlicher, aber noch weit mehr wurde meine Aufmerksamkeit erweckt durch die Vergrösserung der Kerne, welche in gleicher Weise in den Radialfasern und Nervenzellen erfolgte. Die Kerne der Nervenzellen hatten in allen Dimensionen zugenommen, waren rund geworden und hatten oft den halben Durchmesser der Zelle erlangt, dagegen waren die Kerne der Radialfasern zwar auch in allen Richtungen gewachsen, aber doch hauptsächlich in der Richtung der Faser und weniger in der Breite, vielleicht durch die anliegende Wand der Faser gehindert. Die Vergrösserung der Kerne ist nur die Einleitung zur Theilung derselben, welche sich in den Zellen genau verfolgen lässt. Man sieht in den vergrösserten Kernen derselben bald zwei Kernkörperchen, anfangs dicht bei einander, später in den entgegengesetzten Enden der ovalen

•) Observationes de retinæ structura penitiori. 
Kerne; dann schnüren sich die Membran und der Inhalt des Kerns nach und nach ab, und es entstehen so nach Vollendung derselben zwei Kerne in der Zelle, welche sich allmälig ebenfalls von einander entfernen. Diese Vorgänge habe ich in Fig. 5. b, c, d gezeichnet. Dif Theilung der Kerne kann nun noch weiter gehen und einmal habe ich drei getrennte Kerne in einer Zelle gesehen (Fig. 5, d), doch nie mehr als drei und diese auch nur das eine Mal. Es hat die Kerntheilung in der Retina in Bezug auf die Schnelligkeit durchaus keine Achnlichkeit mit der Kerntheilung der Chorioideazellen, allein im Ganzen sind doch beide Vorgänge sich völlig gleich, resultiren aus derselben Ursache und würden vielleicht selbst zu denselben Resultaten führen. Der Yorgang schreitet so langsam vorwärts, dass 25 Tage nach dem Beginn desselben nur einmal drei Kerne zu sehen waren; diesc Langsamkeit muss betont werden, um zu erklären, dass besondere Veränderungen in den Nervenzellen oder vielleicht gar Zerstörung derselben durch ihn nicht im Mindesten zu bemerken waren. Weitere Veränderungen waren an den Kernen nicht zu finden, an der fettigen Degeneration des Zelleninhaltes betheiligte sich der Inhalt der Kerne in keiner WeiseUebrigens war es mir nur möglich, diese Theilungsvorgänge in den Kernen der Nervenzellen zu verfolgen, während ich an den vergrösserten Kernen der Radialfasern nur einmal die Andeutung einer Theilung sah (Fig. 4, c) worin dieser Unterschied zwischen den Kernen der Nervenzellen und denen der Radialfasern beruht, vermag ich nicht anzugeben, vielleicht doch in einem Mangel der Beobachtung.

$7 u$ der Kerntheilung scheint es übrigens nothwendig zu sein, dass die Zelle im Zusammenhange mit der Retina bleibt, demı die gezeichneten Präparate, sowie alle, welche ich sah. habe ich nur der zusammenhängenden 
Membran entnommen, während in den losgerissenen Zellen ich nichts von diesen Vorgängen gesehen habe, doch wäre es allerdings möglich, dass Zellen mit getheilten Kernen erst später losgerissen und so in der Eitermasse gefunden würden. Ks scheint also, wie auch leicht erklärlich, zwischen dem degenerativen Vorgange des Zelleninhaltes und dem productiven des Kerns und der Kernkörperchen ein directer Gegensatz zu bestehen. Die fettige Degeneration zeigt sich in ihrem Beginn allerdings schon, wenn Fasern und Zellen noch innerhalb der geschlossenen Membran sich befinden, allein ihre höchste Stufe, ihr 'Ziel erreicht sie erst, wenn Fasern und Zellen von der Retina losgerisseu sind, und frei in der Eitermasse liegen. Die Theilung und Vermehrung der Kerne dagegen geht nur innerhalb der Membran vor sich und hört auf, sobald als die Zelle aus der Retina ausgetreten ist. Ich muss gestehen, dass mir diese lange hin und her überlegten Vorgänge in gewisser Weise als nicht unwichtige Andcutungen über die von allen Seiten gesuchte Bestimmung der Function der einzelnen Zellentheile erschienen sind. Da diese Bestimmung ohne Zweifel einen sehr hohen Werth hat, so will ich die durch jene Beobachtungen geweckte Vermuthung dahin aussprechen, dass vielleicht dem Inhalt und der Membran der Zelle die Function derselben zuzuschreiben ist, dagegen der Kern und Kernkörperchen der Fortpflanzung und Weiterbildung vorstehen. Der Kern der Zelle kann untergehen und die Function derselben dabei völlig ungeändert bleiben; der Inhalt wieder und die Membran der Zelle können zerstört werden, während der Kern fortlebt, sich vermehrt und durch wiederholte Theilung und chemische Umsetzungen der vorigen Zelle ganz unähnliche Gebilde darstellt.

Da ich über das Schicksal der jetzt zweifelhaft gewordenen granulösen Schicht nichts Bestimmtes anzuge- 
ben weiss, so bleiben noch zwei Schichten der Retina zu erwähnen übrig: die äussere Körnerschicht und die Stäbchenschicht. Im Beginn der Eiterbildung fanden sich in der äusseren Körnerschicht einzelne Körner vergrössert, waren dann nicht mehr völlig rund, sondern eckig, und erschienen granulirt oder selbst grobkrümelig, so dass sie vielleicht ähnliche Metamorphosen eingehen, als die Radialfasern und Nervenzellen, doch nahmen an diesen Veränderungen nur einzelne Körner Theil, die übrigen waren ungeändert. Bei weiterem Verlaufe waren an einzelnen Stellen die Veränderungen ebenso, wie oben beschrieben, an anderen die Schicht zerstört und nun die Elemente derselben unter den Eiterkörperchen, denen sie an Grösse und Aussehen ziemlich nahe kommen, nicht mehr zu verfolgen.

In der äusseren Körnerschicht lagerten besonders die hyalinen Kugeln, welche ich als Schleimkugeln erwähnt habe. Sie werden bei der Untersuchung normaler Retina nur selten gefunden, fanden sich während des Eiterungsprocesses in jedem Retinapräparate, stammten aber aus den äusseren Schichten. Sie lagen überall zwischen den äusseren Körnern, welche sich öfters rund um sie gruppiren. Diese Kugeln sind sehr verschieden gross, oft dreimal so gross als Eiterkörperchen; sie haben keine Membran und bestehen aus einer durchsichtigen glänzenden Masse; häutig enthalten sie kleine Kugeln und sind leicht punktirt, Diese Punktirung tritt bei Essigsäurezusatz jedesmal hervor. Ich halte diese hyalinen Kugeln für ausgetretenen Stäbcheninhalt und glaube, dass der Inhalt durch den Druck der Eiterkörperchen, welche die Seiten der Stäbchen passiren, ausgetrieben wird. Es wird diese Annahme durch das spätere Verhalten der Stäbchen bewiesen, denn man findet von ihnen nur die blassen Membranen ohne jeden Glanz, welcher ihnen erst durch den Inhalt verliehen 
wird. Es wird aus diesem Vorgange auch klar, dass der innere Faden der Stäbchen nicht zu verfolgen ist; ich zweifle übrigens durchaus nicht dass seine Existenz auch bei den höheren Thieren nächstens nachgewiesen werden wird. Abgebrochenc Stücken der Stäbchen sieht man häufig in den Eitermassen schwimmen. Ueber die Zeit, in welcher diese einzelnen Veränderungen verlaufen, kann ich keine Angabe machen, muss aber noch bemerken, dass in derselben Retina an einer Stelle dieselben sich in hohem Grade finden können, während an einer anderen die Membran fast normal erscheint.

So habe ich über das Schicksal der einzelnen Retinaelemente während der Eiterbildung angegeben, was ich gefunden habe, natürlich sind viele Lücken darin auszufüllen. Dass aber nach dieser Frklärung des ganzen Processes der eitrige Retinitis, welche Schweigger*) erwiesen zu haben glauhte, nicht existiren kann, ist wohl erwiesen. Schweigger blieb dabei merkwürdigerweise den Beweis schuldig, wo die Eiterbildung vor sich gehe. Allein die Frage ist doch nicht abzuwenden, ob überhaupt eine Retinitis von pathologisch-anatomischer Seite angenommen werden kann. Ausser den Kernen der Gefässe hat meiner Ansicht die Retina in den Kernen der Nervenzellen und Radialfasern noch Flemente, welche in Folge eines entzïndlichen Reizes sich weiter entwickeln können. Ueber die Kerne der Gefässe habe ich keine Beobachtungen, zweifle aber, dass sie eine solche Entwicklung einschlagen können, ohne sehr hald zum Durchbruch und der Zerstörung der Gefässe zu führen. Die Kernvermehrung der Nervenzellen und Radialfasern ist dagegen als entzündliches Product aufzufassen; $o b$ sie aber dem Begriffe der Retinitis eine genügende Basis unterlegen kann, bin ich doch sehr zweifelhaft und

*) Arohiv für Ophthalmologie. VI. 2. 266. 
möchte vorerst vom anatomischen Standpunkte aus den Namen Retinitis verbannen, da der Retina bis auf jene geringen Andeutungen die entzündungsfähigen Elemente fehlen. Die Retinitis beruht bis jetzt bloss auf Beobachtungen am Lebenden und auf einer Symptomenreihe, welche vielleicht auch andere Deutungen zulässt. Die retinitis pigmentosa allein ist anatomisch festgestellt und sie beruht sicher nicht auf entzündlichen Vorgängen der Retina, sondern auf einer Entzündung der Chorioidea und auf der Zerstreuung des Pigmentes der zerstörten Chorioideaepithelien in die Schichten der Retina. Schon dieser Vorgang hätte auf den Weg hinweisen müssen, den in der Chorioidea gebildeter Eiter nehmen muss. Uebriguns halte ich eine genaue Untersuchung der Entzündungsproducte in den Centralorganen des Nervensystems für eine der nächsten Aufgaben der pathologischen Anatomie.

\section{Verhalten der Linse.}

(Fig. 3.)

1)ie Veränderungen, durch welche die Linse nach geschehener Verwundung die beschriebenen Vorgänge in der Chorioidea und Retina einleitet, habe ich bis jetzt Quellung der Linse genannt, folgend der gewöhnlichen klinischen Bezeichuung; in wiefern dieselbe gerechtfertigt und wie sic aufzufassen ist, liegt nun aus dem anatomischen Befunde zu beweisen vor. In allen vorliegenden Fällen wurde die Linse beträchtlich verwundet, die Reclination derselben wiederholt versucht und die Linsentheile öfters zerstückelt. Ein Theil der nun zu beschreibenden Linsenveränderungen wird daher den im ersten Aufsatze erwähnten Folgen von Reclinationsversuchen völlig gleich sein. Zusammenhängende grosse Theile der Linse, welche auf diese Weise dislocint wurden, verhielten sich bis 
zu einem gewissen Fortschritt des Fiterungsprocesses ganz analog cinfaeh reclinirten Theilen, wenigstens soweit es die imneren Schichten betraf.

Die Linsenkapsel zeigte zu keiner Zeit weder an der vorderen noch an der hinteren Wand irgend pathologische Veränderungen; je nach dem Grade der erfolgten Entleerung war sie in Zipfel gegen den Linsenfalz eingerollt oder um Linsenreste faltig ausgespannt. Die structurlose Membran der Kapsel war immer durchsichtig und klar, das Lpithel der vorderen Kapsel stets von der gewöhnlichen Beschaffenheit, und nie liess sich in den Zellen desselben eine Veränderung bemerken. Von einer Fiterbildung, wie sic C. O. Weber (l. c.) angiebt, labe ich in diesen Fpithelialzellen auch nie die geringste Spur gesehen. Die in dem Falz der Kapsel zurückgebliebenen Fasern, welche also keine Continuitätstrennung erlitten hatten, waren bei jeder Untersuchung ohne jede Aenderung geblieben, durchsichtige, glänzende, glatte Fasern. Nur einmal fand sich im Bereich der Kernzonen der Inhalt aller Kerne in grobe Krümel zerfallen, welche in Essigsäure nicht löslich waren, aber keinen Glanz hatten; nie habe ich von diesen Kernen aus eine Vermehrung der Eiterkörperchen bemerkt und auch in dem erwähnten lalle war die Cohäsion der Fasern so bedeutend, dass ich nicht zu entscheiden vermochte, ob ein oder mehrere Kerne zu einer Faser gehören, ein Punkt, der ja immer noch streitig ist.

Die dislocirten Linsentheile sahen immer trübe durchscheinend aus, an der Oberflüche waren sie alle mehr oder weniger uneben und mit flottirenden Anhängselı besetyt. Im Inneren der grossen Theile fayden sich die Linsenfasern kaum verändert; sie waren leicht punktirt (Fig. 3 c), zwischen den einzelnen Fasern wurden dunkle Zwischenräume sichtbar, und die sonst immer parallelen Contouren waren unregelmässig gezackt. Die Punktirung 
schwand in lissigsiume. I)as Auftreten der Zwischenräume und die Unregelmässigkeiten der Contouren halte ich für Ausdrücke der Cohäsionsverringerung zwischen den einzeluen Fasern, welche durch chemische Umsetzungen des Faserinhaltes hervorgerufen ist. Gegen die Oberfläche hin nehmen die Veränderungen immer mehr zu, die Punktirung wird bedeutend, weht durch die ganze Faser, der Glanz derselben und die Inurchsichtigkeit verschwindet, die Zwischenräume werden breiter, dunkler, und die Lnregelmässigkeiten der Contouren stärker. An der Oberflïche selbst begegnet man num den eigentlich charakteristischen Veränderungen; hicr haben die Fasern fast allen Zusammenhang verloren, die meisten sind nur an einer kleinen Stelle mit anderen verbunden und flottiren mit dem losgerissenen Fnde frei herum, dabei sind die Contouren hin- und hergebogen, meist aber ist die Punctirung nicht so sehr erheblich, sondern Durchsichtigkeit und Glanz der I'asern ziemlich crhalten. Noch weiter gehen diese Veränderungen in den Fascrn, welche völlig aus allem Zusammenhange mit den übrigen Fascrn losgerissen in der Eitermasse liegen. ILier kreuzen sich die Linsenfasern wild durcheinander, sie sind in allen richtungen gebogen, ohne jede Verbingung untereinander frehen sie sich in diesen libgungen wieder anf sich zurück; ihre ('ontouren sind zalckig und öfters buchtig ausgedehnt, so dass sie kleine rundliche Höhlungen bilden (Fig. $3 \mathrm{~b}$ ); dic Durchsichtigkeit ist bewahrt, der Glanz abor nur matt, ausser an Stellen, wo die Fasern spiralförmige Drehumgen um sich selbst machen. Leberall lagern sich in die \%wischenräume, welche die Iinsenfasern zwischen sich lassen, Eiterkörperchen. Janu finfen sich aber zwischen diesen lifementen yerstrent zahlreiche, slänzcnde, scharfontourirte Kugeln von schr ver schiedener Girüsse, welcho sich von den früher erwähnten schleintiggeln in der lictina durch ihren filanz und 
scharfe Contour sehr leicht unterscheiden. Sie haben kein Membran, erreichen oft eine sehr bedeutende Grösse und schliessen dann eine oder zwei, selbst drei kleinere Kugeln in sich, bei Essigsäure-Zusatz werden sie punctirt und sind entschieden als ausgeflossener Inhalt der Linsenfasern zu betrachten, da sie denselben an Glanz. und Durchsichtigkeit völlig analog sind.

Dislocation und Verwundung der Linse ergaben das erste Moment dieser Vorgänge, und es ist daher woll natürlich, dass man in den Fällen, in welchen die Zerstückelung der Linse eine bedeutende war, auch weit mehr zertrümmerte Linsenfragmente finden wird; doch sind mit Ausnahme hiervon die übrigen Veränderungen sich immer gleich und entsprechen auch in ihrem Fortschritt weit mehr der Zeit, welche sie gedauert haben, als der Intensität des Eingriffes.

Man sieht allerdings hieraus, dass der Ausdruck Quellung der Linse in gewisser Weise seine Berechtigung hat; es beruht die Berechtigung dieser Benennung darin, dass den inneren Augenhäuten durch die Vorgänge reizende, irritirende Berührungspuncte gegeben werdon. Diese Berührungspuncte finden sich einmal in dem Unregelmässigwerden der Contouren und in dem Austreten der Inhaltskugeln, am meisten aber meiner Meinung nach in der Kräuselung der Fasern. Diese stellt gewiss eine Bowegung der Fasern vor, welche durch die chemischen Veränderingen und dic Trennung der Fasern eingeleitet wird und in ihrem Endresultate zur eitrigen Entzündung der Chorioidea fülırt. -

Auf die weiteren Veränderungen der Linse muss der Eiterungsprocess selbst vom grössten Einfluss sein, durch ihn werden sicher bedeutende Continuitätstrennungen und chemische Umsetzungen eingeleitet, welche in späterer Zeit zur Atrophie der Linse fïhren. Die Verwandlung des Faserinhaltes wird der erste Anfang dieser 
Atrophic sein; übrigens zeigen dio Sectionen atronhischer Augen häufig genug, dass immer Reste der Linse zurückbleiben. - Auch im Retreff der Linse sind also nur die Anfänge und die Richtung aller Veränderungen angedeutet; man sieht übrigens doch im Ganzen die Wege, auf welchen der Eiterungsprocess, wie überall, so anch hier Atrophic und Schwund der Organe vorbereitet. Dass dic in der Capsel zurückgebliebenen Linsentheile später ähnlichen Umwandlungen verfallen müssen, ist wohl erklärlich.

\section{Verhalten der Sclera, Cornea und Conjunctiva.}

Die Sclera fand ich während dieser Vorgänge selbst an den Einstichspuncten der Nadel immer ungeändert. Dagegen entwickelte sich immer gleich im Anfange des Processes beträchtliche Gefässbildung in dell ganzen Conjunctivalsacke und ein gewisser Grad ron Chemosis. Nach wenigen Tagen häufen sich die Gcfässe der Conjunctiva um den Rand der Cornea, überschreiten diesen anfangs nur am unteren Rande, später aber ringsum und bilden auf der Hornhaut radiäre, ziemlich mächtige und zahlreiche Gefässe, welche untereinander durch seitliche Aeste anastomosiren. Sie schreiten alluälig weiter gigen den Mittelpunct der Cornea vor, hatten ihn aber am 25. Tage noch nicht ganz erreicht. Zwischen ihnen erscheint das Gewebe der Hornhaut leicht getriibt, auch wenn keine Exsudatmasse an der hinteren Wand der Cornea eine genaue Beurtheilung derselben verhindert. Der schwarze Rand der Cornea, wolcher sich beim Kíaninchen, wic bei vielen anderen Thieren findet, wird durch die Gefissbildung völlig verwaschen.

Bei der Untersuchung solcher Hornhäute findet man den Theil derselben, wo dic neugubildeten Gefasse liegen, 
ausserordentlich morsch, so dass feine Durchschnitte an frischen Präparaten ganz mumöglich sind. Man sieht bei der mikroskopisclen Untersuchung überall zahlreiche, starke Gefassc, nicht von dem Charakter der Capillaren, sondern zum grössten Theil von einer Ringfaserhaut umgeben. Zwischen den Gefässen war die Substanz der Hornhaut nur wenig verändert; die Intercellularsubstanz war klar und ohne jede Spur von Trübung; die Hornhautkörperchen waren allerdings nach allen Seiten hin ausgedehnt durch die entschieden vergrösserten Kerne, nur einmal habe ich aber eine Kerntheilung verfolgen können und diese war so vereinzelt, dass ich auf sie durchaus keinen Werth für den ganzen Process legen kann. Indem ich also keine Zellenbildung beobachtet habe, muss ich für die Gefässbildung auf dic Schlängelung und Verzweigung der Conjunctivagefïsse alles Gewicht legen. 

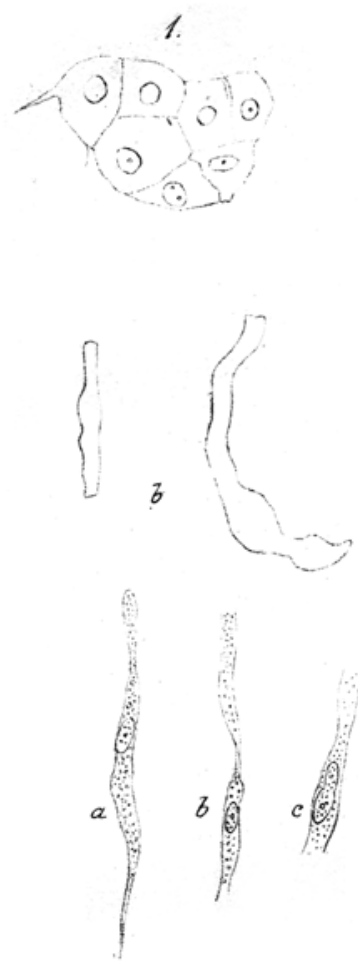

4.

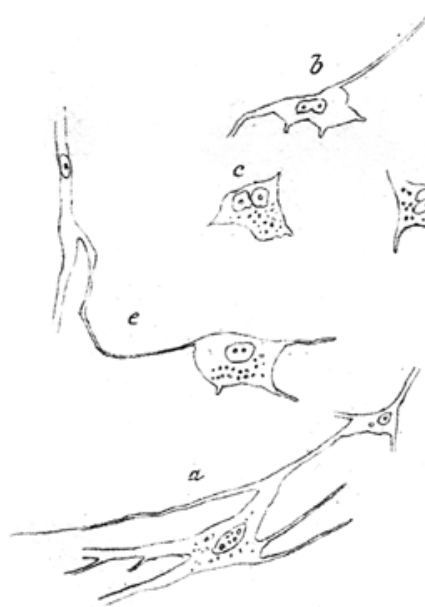

$$
\begin{aligned}
& 0,00000 \\
& 6
\end{aligned}
$$

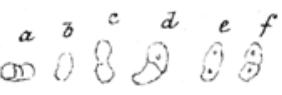

5.

$\frac{c}{30}$.
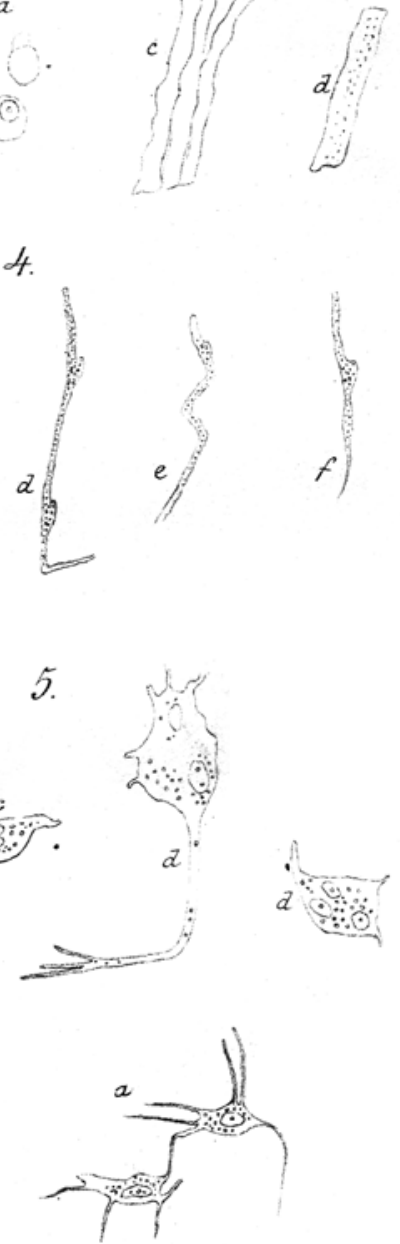


\section{Erklärung der Tafel.}

Fig. 1. Epithel der Glaskörperhaut zusammenhängend.

Fig. 2. Einzelne Zellen desselben durch Verfettung des Inhaltes im Uebergange zu Körnchenzellen.

b. zeigt die Aeste der Zellen.

Fig. 3. Veränderungen der Linse während des Eiterungsprocesses.

a. ausgeflossener Inhalt der Linsenfasern.

b. einzelne zackige und ausgebuchtete Fasern mit leichter Punctirung.

c. zusammenhängendes Stück.

d. feine Punctirung der Fascrn im Innern grosser Theile.

Fig. 4. Veränderungen der Radialfasern während des Eiterungsprocesses.

a. b. c. Breitwerden der Fasern, Punctirung des Inhaltes und Wachsen der Kerne.

c. Beginn der Kerntheilung.

d. e. f. Verfettung des Inhaltes, besonders der inneren Körner.

Fig. 5. Veränderungen der Nervenzellen während des Eiterungsproceses.

a. losgerissene Nervenzellen mit sehr vielen Aesten, unter sich zusammenhängend.

b. c. d. Theilung und Vermehrung der Kerne.

c. d. e. Verfettung des Zelleninhaltes.

e. Zusammenhang einer Nervenzelle mit einer kernhaltigen Radialfaser.

Fig. 6. Theilung der Kerne der Chorioideazellen in Eiterkörperchen und deren weitere Entwicklung. (Abheben der Membran vom Inhalt.)

(Die Vergrösserung bei allen Präparaten ist 300 .) 